\title{
Silicon Carbide
} Temperature Monitor Measurements at the High Temperature Test Laboratory

J. L. Rempe

K. G. Condie

D. L. Knudson

L. L. Snead

January 2010

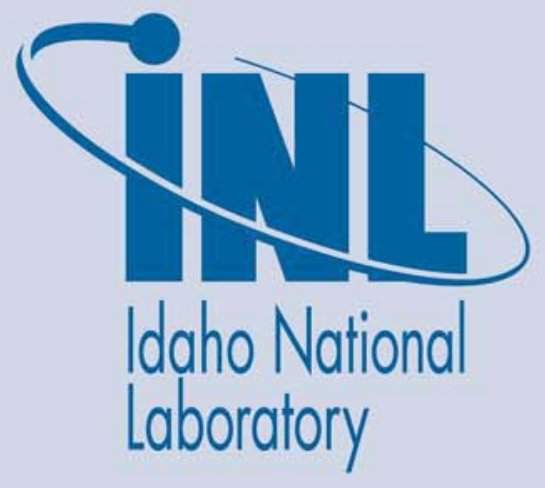

The INL is a U.S. Department of Energy National Laboratory operated by Battelle Energy Alliance 
INL/EXT-10-17608

\title{
Silicon Carbide Temperature Monitor Measurements at the High Temperature Test Laboratory
}

\author{
J. L. Rempe \\ K. G. Condie \\ D. L. Knudson \\ L. L. Snead
}

January 2010

\author{
Idaho National Laboratory \\ Idaho Falls, Idaho 83415 \\ http://www.inl.gov
}

\author{
Prepared for the \\ U.S. Department of Energy \\ Office of Nuclear Energy \\ Under DOE Idaho Operations Office \\ Contract DE-AC07-05ID14517
}




\section{DISCLAIMER}

This information was prepared as an account of work sponsored by an agency of the U.S. Government. Neither the U.S. Government nor any agency thereof, nor any of their employees, makes any warranty, express or implied, or assumes any legal liability or responsibility for the accuracy, completeness, or usefulness of any information, apparatus, product, or process disclosed, or represents that its use would not infringe privately owned rights. References herein to any specific commercial product, process, or service by trade name, trademark, manufacturer, or otherwise, does not necessarily constitute or imply its endorsement, recommendation, or favoring by the U.S. Government or any agency thereof. The views and opinions of authors expressed herein do not necessarily state or reflect those of the U.S. Government or any agency thereof. 



\section{CONTENTS}

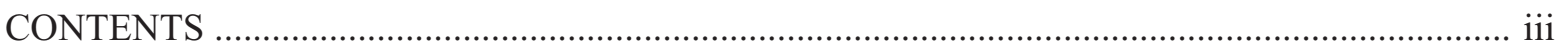

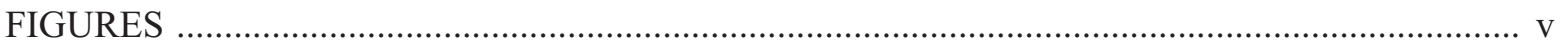

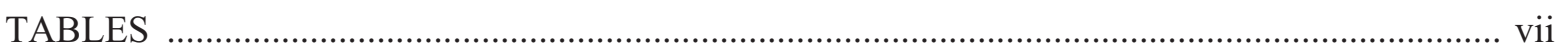

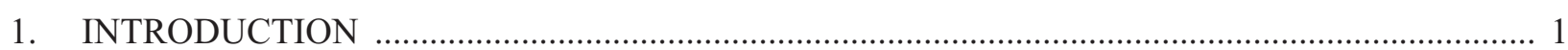

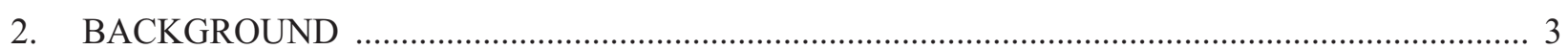

3. EQUIPMENT SETUP AND CHECKOUT ….................................................................... 7

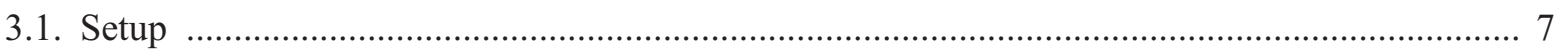

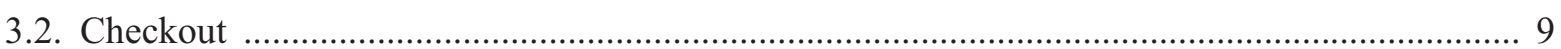

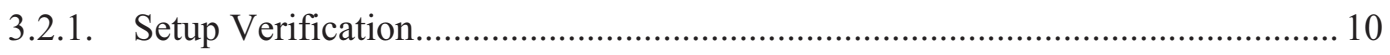

3.2.2. Room-Temperature SiC Resistivity Measurements ............................................ 11

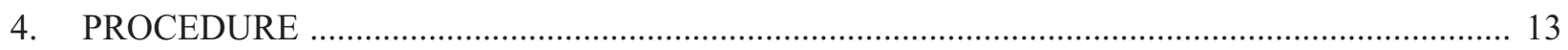

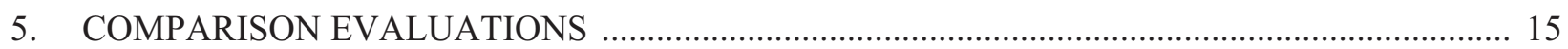

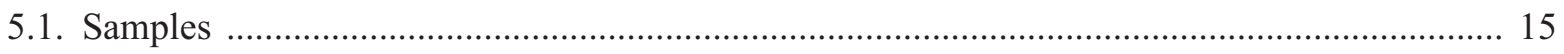

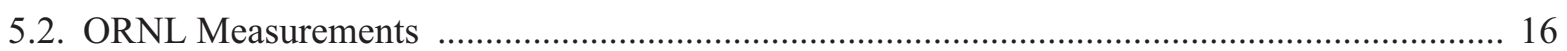

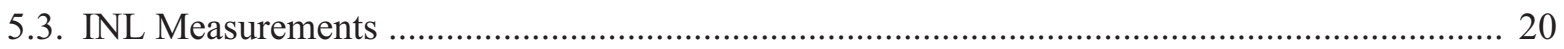

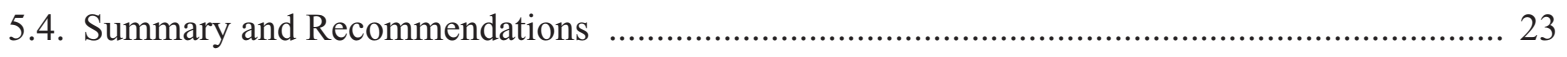

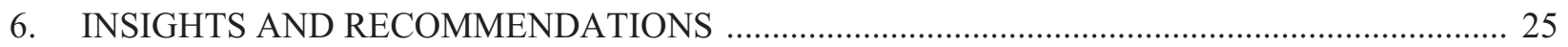

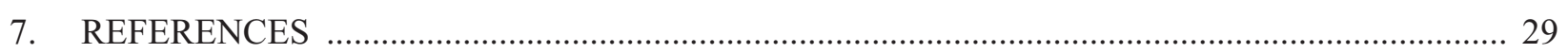

APPENDIX A - SAMPLE SiC TRAVELER …........................................................................... A-1 


\section{FIGURES}

2-1. Saturation linear expansion of $\mathrm{SiC}$ as a function of irradiation temperature. ${ }^{6,7}$.......................... 3

2-2. Comparison of in-situ thermocouple and post-irradiation $\mathrm{SiC}$ monitor temperatures. ${ }^{2}$................. 4

2-3. Electrical resistivity technique applied over a range of irradiation temperatures. ${ }^{2}$....................... 5

3-1. Setup for annealing and measuring SiC temperature monitors ............................................... 7

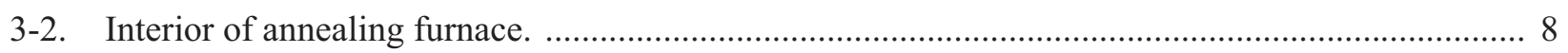

3-3. Measured difference in temperature in calibrated and furnace thermocouples. ............................. 8

3-4. Close-up of INL fixturing for making electrical measurements. .............................................. 10

5-1. ORNL fixturing for electrical measurements. ............................................................................ 17

5-2. Electrical resistivity of the 18J SiC temperature monitor "no ID" (resistivity values calculated by ORNL from measured voltage and constant current) 17

5-3. Electrical resistivity of the $18 \mathrm{~J} \mathrm{SiC}$ temperature monitor "R2"(resistivity values calculated by ORNL $\begin{array}{ll}\text { from measured voltage and constant current) } & 18\end{array}$

5-4. Measured voltage for the LO 3085 mirror temperature monitor (obtained by ORNL with constant current).

5-5. Measured voltage for the LO 3090 mirror temperature monitor (obtained by ORNL with

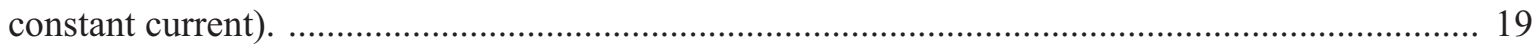

5-6. Measured voltage for the LO 3097 mirror temperature monitor ................................................. 19

5-7. Electrical resistivity of the 18J SiC temperature monitor "HFIR BB2W." ................................. 21

5-9. Electrical resistivity for the LO 3097 mirror temperature monitor ............................................ 22

5-8. Electrical resistivity for the LO 3090 mirror temperature monitor. ............................................ 22

5-10. Comparison of results obtained by INL (HFIR BB2W) and ORNL (HFIR R2 and no-ID) for samples heated in the $18 \mathrm{~J}$ test. 23

5-11. Comparison of INL and ORNL results for L03090 (INL data only included after power analyzer settings were optimized for low current measurements). 24

5-12. Comparison of INL and ORNL results for L03097.

6-1. Comparison of INL (BB2W) and ORNL (R2 and no-ID) results for samples heated in the $18 \mathrm{~J}$ test.

6-2. Comparison of INL and ORNL results for LO 3090 samples (INL data only included after power analyzer settings were optimized for low current measurements).

6-3. Comparison of INL and ORNL results for LO 3097 samples. 


\section{TABLES}

2-1. Comparison of various $\mathrm{SiC}$ temperature monitor measurement techniques. ${ }^{2,13}$........................... 4

3-1. SiC grades available from Rohm and Haas. ................................................................................ 11

3-2. Initial INL SiC room temperature resistivity measurements .................................................. 12

5-1. Round-robin temperature monitor measured by each laboratory ….......................................... 15

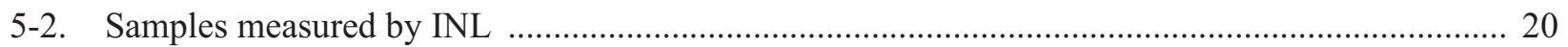

5-3. Round-robin temperature monitor results .................................................................................. 23

6-1. Round-robin temperature monitor summary results ................................................................ 25 


\section{INTRODUCTION}

Silicon carbide $(\mathrm{SiC})$ temperature monitors are now available for use as temperature sensors in Advanced Test Reactor (ATR) irradiations. Although thermocouples are used to provide real-time temperature indication in instrumented lead tests performed at materials and test reactors, other indicators, such as melt wires or paint spots, are also often included in such tests as an independent technique of detecting peak temperatures incurred during irradiation. In addition, less expensive static capsule tests, which have no leads attached for real-time data transmission, often rely on melt wires and paint spots as a post-irradiation technique for peak temperature indication. Melt wires and paint spots are limited in that they can only detect whether a single temperature is or is not exceeded. SiC monitors are advantageous because a single monitor can be used to detect for a range of temperatures that occurred during irradiation.

As part of the process initiated through the ATR National Scientific User Facility (NSUF) program to make $\mathrm{SiC}$ temperature monitors available, a capability was developed at the Idaho National Laboratory (INL) to complete post-irradiation evaluations of these monitors. As discussed in this report, INL selected the resistance measurement approach for determining irradiation temperature from SiC temperature monitors. This document describes the INL process to establish the capability to complete these resistance measurements. In addition, the procedure is reported that was developed to assure that high quality measurements are made in a consistent fashion.

Section 2 provides background information on prior efforts to use $\mathrm{SiC}$ as monitors to determine irradiation temperature. Sections 3 and 4 describe the equipment installed and the procedure used at INL's High Temperature Test Laboratory (HTTL) to allow examination of irradiated SiC temperature monitors. To demonstrate the newly developed $\mathrm{SiC}$ temperature capability, comparison measurements were completed using identically irradiated $\mathrm{SiC}$ temperature monitors. Results from these comparison measurements are provided in Section 5. General insights and recommendations from this effort are summarized in Section 6. References cited in this document are listed in Section 7. Appendix A of this document contains a sample traveler used for completing $\mathrm{SiC}$ temperature monitor evaluations. 
INL/EXT-10-17608 


\section{BACKGROUND}

Since the early $1960 \mathrm{~s}$, SiC has been used as a post-irradiation temperature monitor. Pravdyuk ${ }^{1}$ first reported that neutron irradiation induced lattice expansion of silicon carbide annealed out when the postirradiation annealing temperature exceeds the irradiation temperature. Snead ${ }^{2}$ reports that this swelling has been associated with lattice dilation from point defect formation, ${ }^{3}$ though recent modeling has suggested that small interstitial clusters may also impact swelling. ${ }^{4}$ Swelling saturates at fluences of $<5 \times 10^{21} \mathrm{n} / \mathrm{cm}^{2}$ $(\mathrm{E}>0.1 \mathrm{MeV})^{5,6}$ with an absolute change being a strong function of temperature. Figure $2-1^{2}$ shows measured linear expansion that can be expected from fully dense $\left(3.203 \mathrm{~g} / \mathrm{cm}^{3}\right)$, pyrolitic SiC.

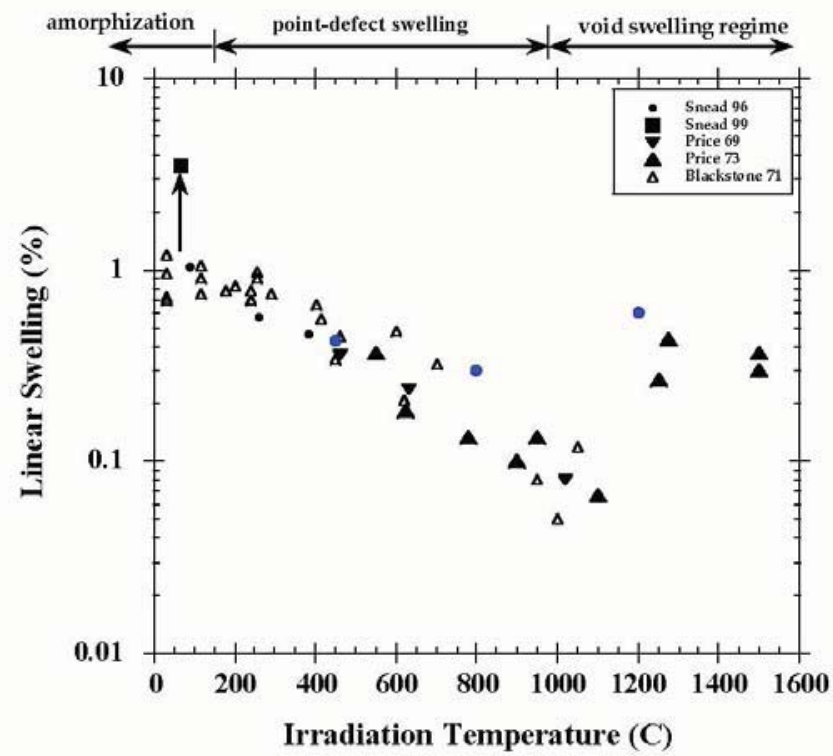

Figure 2-1. Saturation linear expansion of $\mathrm{SiC}$ as a function of irradiation temperature., 6

$\mathrm{SiC}$ monitors are typically applied for constant-temperature irradiations from 200 to $1000{ }^{\circ} \mathrm{C}$. Initially, temperatures from $\mathrm{SiC}$ monitors were primarily inferred from length measurements after isochronal annealings. As reported in Reference 2, several researchers investigated other techniques, such as X-ray line broadening to detect lattice parameter changes, ${ }^{8,9}$ thermal diffusivity, density, and electrical conductivity ${ }^{10}$ without showing any improvement over length change techniques. With the use of precise length measurement techniques, Price ${ }^{10}$ claims accuracies between 20 and $30^{\circ} \mathrm{C}$, depending on irradiation temperature. However, investigations by Palentine, ${ }^{11}$ which were later confirmed by Maruyama, ${ }^{12}$ found errors as large as $100{ }^{\circ} \mathrm{C}$ with similar length measurement techniques.

In Reference 2, Snead et al. recommend using changes in electrical resistivity because of improved accuracy, ease of measurement, and reduced costs. Information in Table 2-1 (from References 2 and 13) indicates that electrical resistivity measurements offer improved accuracy because samples experience large resistivity changes during annealing and because electrical resistivity can be measured very precisely. Work presented in Reference 2 was conducted on $\mathrm{SiC}$ produced via chemical vapor deposition (CVD). As noted in Reference 2, the large variation of resistivity observed in CVD SiC (from 1 to $10^{5}$ $\mathrm{ohm}-\mathrm{cm}$ ) is primarily dependent on the level of dopant impurities. Hence, Reference 2 authors stress that the $\mathrm{SiC}$ material should be fully dense $\left(3.203 \mathrm{~g} / \mathrm{cm}^{3}\right)$ and stoichiometric. Furthermore, because SiC is temperature-dependent, Reference 2 emphasizes that measurements should be taken in a controlled environ- 
ment (within $0.4{ }^{\circ} \mathrm{C}$ ) for isochronal annealing periods of approximately 30 minutes to obtain the accuracies listed in Table 2-1.

Table 2-1. Comparison of various $\mathrm{SiC}$ temperature monitor measurement techniques. ${ }^{2,13}$

\begin{tabular}{|c|c|c|c|c|}
\hline Technique & $\begin{array}{c}\text { Measurement } \\
\text { Accuracy } \mathbf{( \% )}\end{array}$ & $\begin{array}{c}\text { Property recovery upon anneal } \\
\mathbf{( \% / 1 0} \mathbf{C} \text { anneal) }\end{array}$ & $\begin{array}{c}\text { Property recovery/ } \\
\text { accuracy }\end{array}$ & Accuracy \\
\hline Dimensional Change & 0.05 & $\sim 0.007$ & $\sim 0.3$ & $12-100^{\circ} \mathrm{C}$ \\
Electrical Resistivity & $0.01-1$ & $\sim 0.3$ & $\sim 0.03$ & Less than $20^{\circ} \mathrm{C}$ \\
Thermal Conductivity & $3-5$ & $\sim 0.08$ & $\sim 13$ & Within $25^{\circ} \mathrm{C}$ \\
Density Gradient Column & $\sim 0.02$ & 0.02 & NA & Within $20^{\circ} \mathrm{C}$ \\
Lattice Spacing & $\mathrm{NA}^{\mathrm{a}}$ & $\mathrm{NA}$ & Unknown \\
\hline
\end{tabular}

a. NA- Not Available

Comparisons of temperatures inferred from $\mathrm{SiC}$ measurements and thermocouple data indicate that accuracies of approximately $20^{\circ} \mathrm{C}$ are possible for dose ranges of 1 to $8 \mathrm{dpa}$ and temperatures from 200 to at least $800{ }^{\circ} \mathrm{C}$. Absolute temperature limits for resistivity techniques are typically stated as $150{ }^{\circ} \mathrm{C}$ (an amorphorous threshold) and $875{ }^{\circ} \mathrm{C}$ (due to recrystallization), but Reference 13 indicates that electrical resistivity techniques may also provide insights beyond these temperature limits.

Figure 2-2 shows data obtained from a SiC sample irradiated in the 14J experiment in the Oak Ridge National Laboratory (ORNL) High Flux Isotope Reactor (HFIR). ${ }^{2}$ The test capsule contained a thermocouple embedded in a graphite holder with a Rohm Haas CVD SiC sample. The curve in Figure 2-2 indicates that the $\mathrm{SiC}$ temperature monitor resistivity increases at $\sim 500^{\circ} \mathrm{C}$, which is within $20^{\circ} \mathrm{C}$ of the peak temperature measured by the thermocouple during irradiation. Results in Figure 2-2 are representative of data obtained from this technique. As indicated in this figure, the peak irradiation temperature is identified when data extend beyond a band corresponding to the maximum and minimum values measured at low temperatures and continues to exponentially increase (or decrease) with increasing temperature anneals.

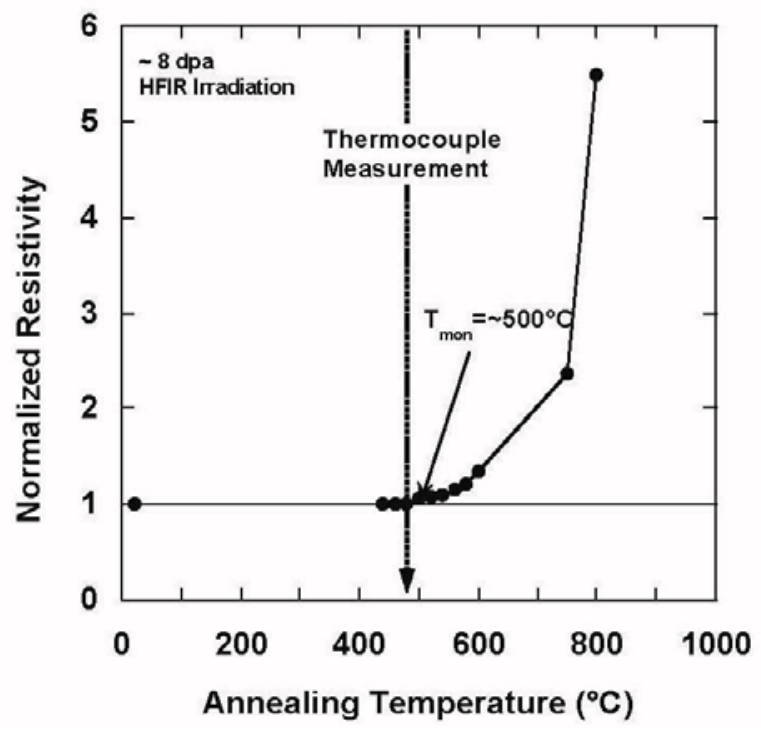

Figure 2-2. Comparison of in-situ thermocouple and post-irradiation $\mathrm{SiC}$ monitor temperatures. ${ }^{2}$ 
Curves in Figure 2-3 (from Reference 2) show data obtained from a series of SiC samples, all irradiated in the ORNL HFIR core at similar dose rates of $\sim 8 \times 10^{14} \mathrm{n} / \mathrm{cm}^{2}$-s $(\mathrm{E}>0.1 \mathrm{MeV})$. The total dose received by each sample differs. The curve for an irradiation temperature of $\sim 350{ }^{\circ} \mathrm{C}$ is at the lowest dose $\left(\sim 0.1 \mathrm{dpa}\right.$, assuming $\left.1 \mathrm{dpa}=1 \times 10^{21} \mathrm{n} / \mathrm{cm}^{2} ; \mathrm{E}>0.1 \mathrm{MeV}\right)$ while the remainder are from $\sim 1-8 \mathrm{dpa}$. In Reference 2 , it is speculated that the apparent saturation in normalized resistivity for the $0.1 \mathrm{dpa}$ sample represents the point at which annealing of the simplest of defects in the irradiated SiC occurs.

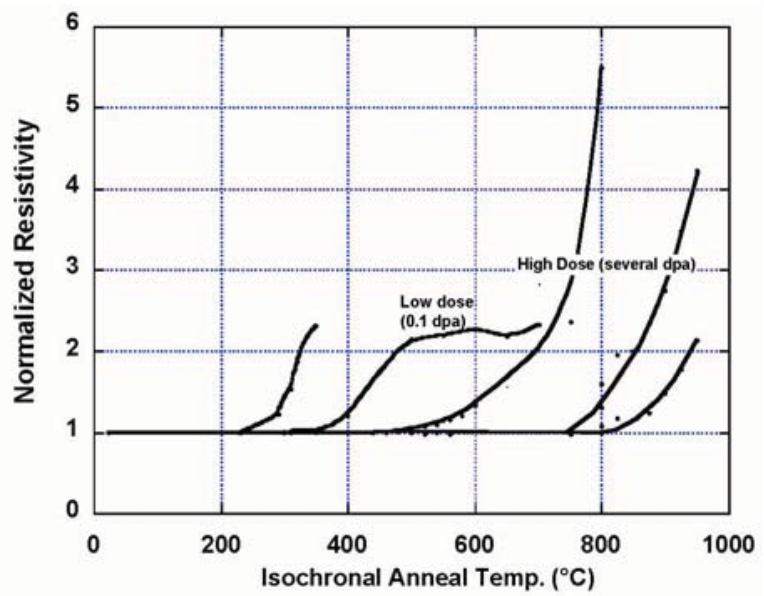

Figure 2-3. Electrical resistivity technique applied over a range of irradiation temperatures. ${ }^{2}$

There are several limitations associated with the use of $\mathrm{SiC}$ temperature detectors. As discussed above, temperatures are inferred by post-irradiation detection of changes in the stable defect population within $\mathrm{SiC}$ monitors that were incurred during irradiation. Higher accuracies are possible if the monitors are obtained from fully dense $\left(3.203 \mathrm{~g} / \mathrm{cm}^{3}\right), \mathrm{CVD} \mathrm{SiC}$ and if the monitors are irradiated at a constant temperature. Reference 15 cites several specific examples where errors could be inferred from SiC monitor measurements:

- Irradiation temperatures rising during the latter part of irradiation. SiC swelling saturates at low fluence. For damages greater than $>0.1 \mathrm{dpa}$, the increasing temperature will anneal out defects that occur at the lower irradiation temperature, while creating stable defects at the higher temperature. When isochronal annealing is performed, lower temperature defects (to some or great extent) will have already been removed, and the recovery curve will be smeared to somewhat higher temperatures. If the temperature increase during irradiation is not great, or the time at higher temperature not too long, then the original departure from linearity will still give the earlier irradiation temperature.

- Irradiation temperatures decreasing during irradiation. This decrease will lead to defects being created and frozen-in at the higher-temperature, while continuing to create lower temperature defects. The isochronal anneal will then give an indication of the lowest irradiation temperature (in this case at the end of the irradiation period) and the recovery curve will be smeared because it will continue to anneal higher and higher temperature stable defects.

- Upward or downward temperature spikes during irradiation. Depending on the time at temperature the effect will be to smear the recovery curve.

However, if irradiation tests are conducted at or near the same temperature when the reactor is at power, none of these situations are of concern. 
INL/EXT-10-17608 


\section{EQUIPMENT SETUP AND CHECKOUT}

As discussed in Section 2, ORNL has successfully measured changes in resistivity to detect peak irradiation temperatures between 200 and $800{ }^{\circ} \mathrm{C}$ with accuracies of approximately $20{ }^{\circ} \mathrm{C}$. INL has recently developed a capability similar to that reported by ORNL for detecting peak irradiation temperature. This section describes the INL-procured equipment, its setup, and initial activities to verify the performance of this equipment.

\subsection{Setup}

Figure 3-1 shows the equipment at INL's High Temperature Test Laboratory (HTTL) that has been configured to measure resistivity of $\mathrm{SiC}$ monitors after annealing. SiC monitors (approximately 0.5 to $2 \mathrm{~mm} \times 0.5$ to $2 \mathrm{~mm} \times 10$ to $25 \mathrm{~mm}$ ) are heated to a temperature ranging from 200 to $800{ }^{\circ} \mathrm{C}$ (where the annealing temperature range is selected to encompass peak irradiation temperatures predicted by thermal analyses for these specimens). The Carbolite $1100{ }^{\circ} \mathrm{C}$ Economy Box furnace used to heat these samples is placed under a ventilation hood located within the stainless steel enclosure. The ventilation system is activated during heating so that any released vapors are vented through this system.

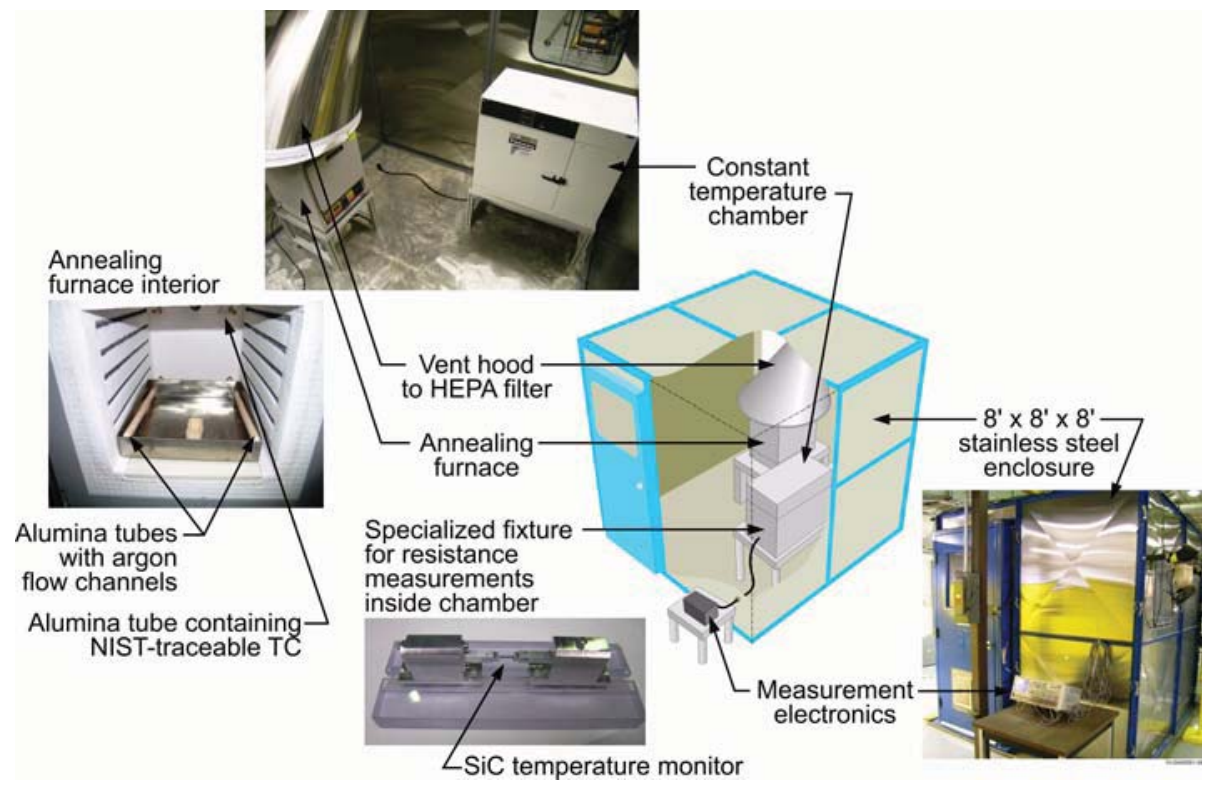

Figure 3-1. Setup for annealing and measuring SiC temperature monitors

Several modifications were made to the furnace in this setup to facilitate $\mathrm{SiC}$ temperature monitor annealing. Temperature accuracy in this furnace is verified using a calibrated thermocouple inserted into furnace. Figure 3-2 shows the alumina tube that contains this thermocouple close to the top of the furnace. The outer two alumina tubes contain thermocouples provided by Carbolite for control and over-temperature protection. Figure 3-3 compares data obtained from the calibrated thermocouple with the furnace setpoint. Values were found to vary from approximately 2 to $9{ }^{\circ} \mathrm{C}$ (depending on furnace temperature). 


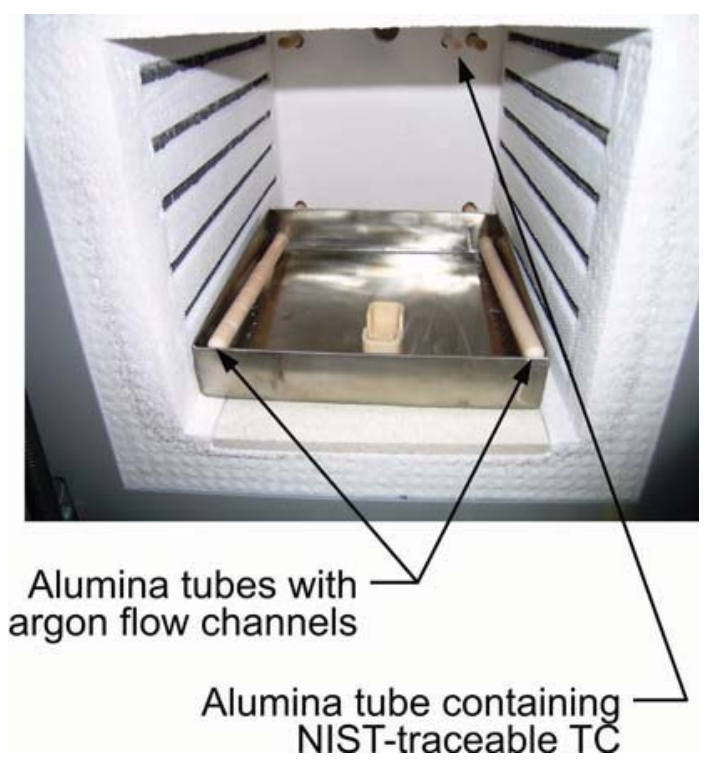

Figure 3-2. Interior of annealing furnace.

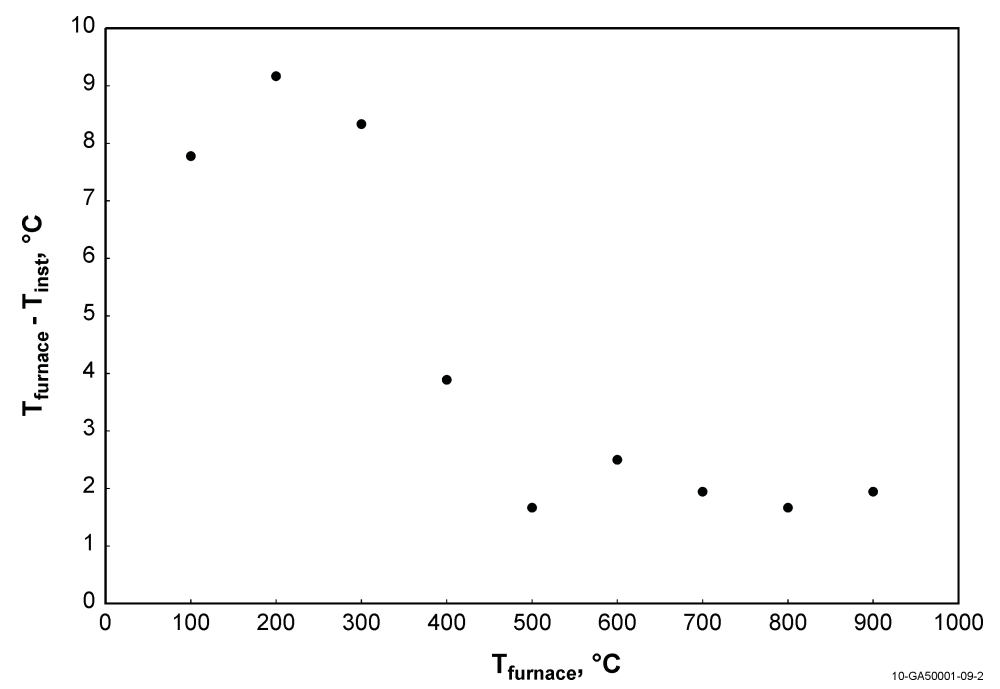

Figure 3-3. Measured difference in temperature in calibrated and furnace thermocouples.

During heating, samples are placed in the alumina crucible shown in Figure 3-2. Reference 15 indicates that care must be taken to address surface silica formation if annealing temperatures exceed $600{ }^{\circ} \mathrm{C}$ in an air atmosphere. One option is to soak annealed samples in a dilute hydrofluoric wash. However, the location where the HTTL is located, Central Facilities Area Building 622 (CFA 622), has not been configured with a fume hood. Hence, an alternate approach, purging the annealing furnace with an inert gas, was implemented by INL to preclude silica formation during such tests. Figure 3-2 shows a stainless steel pan with the alumina crucible and two alumina tubes with flow channels for the purge gas. During heating, samples are placed in this alumina crucible for $30 \pm 2$ minutes. To preclude surface silica formation if annealing temperatures exceed $600{ }^{\circ} \mathrm{C}$ in an air atmosphere, INL purges the annealing furnace with argon gas having a minimum purity of $99.999 \%$ (corresponding with the ultra-high purity or Grade 5 classifica- 
tion) using the two alumina tubes with flow channels. To preclude $\mathrm{SiC}$ oxidation, the argon is provided to the furnace with a flowrate of at least 200 liters/minute for at least 30 minutes prior to $\mathrm{SiC}$ monitor insertion (Gas flow is monitored using a flowmeter calibrated to INL standards).

After heating, the samples are placed into a Tenney Junior Benchtop Test Chamber where current and voltage measurements are taken. This constant temperature environmental test chamber is used to ensure electrical measurements are taken within $0.2{ }^{\circ} \mathrm{C}$ of a predetermined temperature, $30^{\circ} \mathrm{C}$. Temperature stability within this furnace is verified by comparing furnace temperatures with the temperature from a calibrated thermocouple into the constant temperature chamber. Hence, the INL measurements are within the Reference 15 recommendation that electrical measurements be taken to within $0.4{ }^{\circ} \mathrm{C}$ of the same temperature or it will adversely affect the accuracy of resistance values estimated for SiC temperature monitors (see Section 2). A high accuracy (9 digit) Agilent Model N6705A DC Power Analyzer with a calibrated N6762A Precision Power Modules is used to obtain electrical measurements. This power analyzer, which was placed outside the stainless steel enclosure, is capable of applying constant voltages ranging from 1.5 $\mathrm{mV}$ to $50 \mathrm{~V}$. For typical INL measurements, a constant voltage of approximately $20 \mathrm{~V}$ was applied, resulting in microamp current flow.

As noted in Section 2, electrical measurements must be taken on the same portion of the SiC monitor. Figure 3-4 shows a close-up of the specialized fixturing developed by INL with a sketch illustrating the process used to make these measurements. A four point probe technique is used with the four points connected to the sample through spring-loaded angled aluminum electrodes that hold the SiC temperature monitor in place. Current and voltage are provided to the sample through wires that are threaded through the holes in the electrodes. The power analyzer applies a constant voltage to the sample. Then, the sample resistivity is calculated using the measured voltage and current as shown in Figure 3-4.

The resistivity, $R$ ', in ohm-m, is calculated using Equation (3-1)

$R^{\prime}=\frac{V A}{I L}$

$$
\begin{aligned}
& \text { where } \\
& V \quad=\text { measured voltage (volts) } \\
& I=\text { current resulting from the power supply voltage (amps) } \\
& L \quad=\text { sample length (m), and } \\
& A \quad=\text { sample cross-sectional area }\left(\mathrm{m}^{2}\right)
\end{aligned}
$$

As suggested in Reference 16, the ohmic nature of the sample is first evaluated (e.g., the measured current changes in direct proportion to the applied voltage). Then, a voltage is selected that minimizes resistance heating of the sample. This is done by applying a specified voltage and noting whether there is a rapid change of the measured current in one direction. In addition, the voltage is selected that yields a measurable current for this power analyzer.

\subsection{Checkout}

Prior to use, several factors were evaluated to verify the suitability of the INL setup. Section 3.2.1 provides an overview of these factors. Section 3.2.2 describes results from evaluations completed to address 


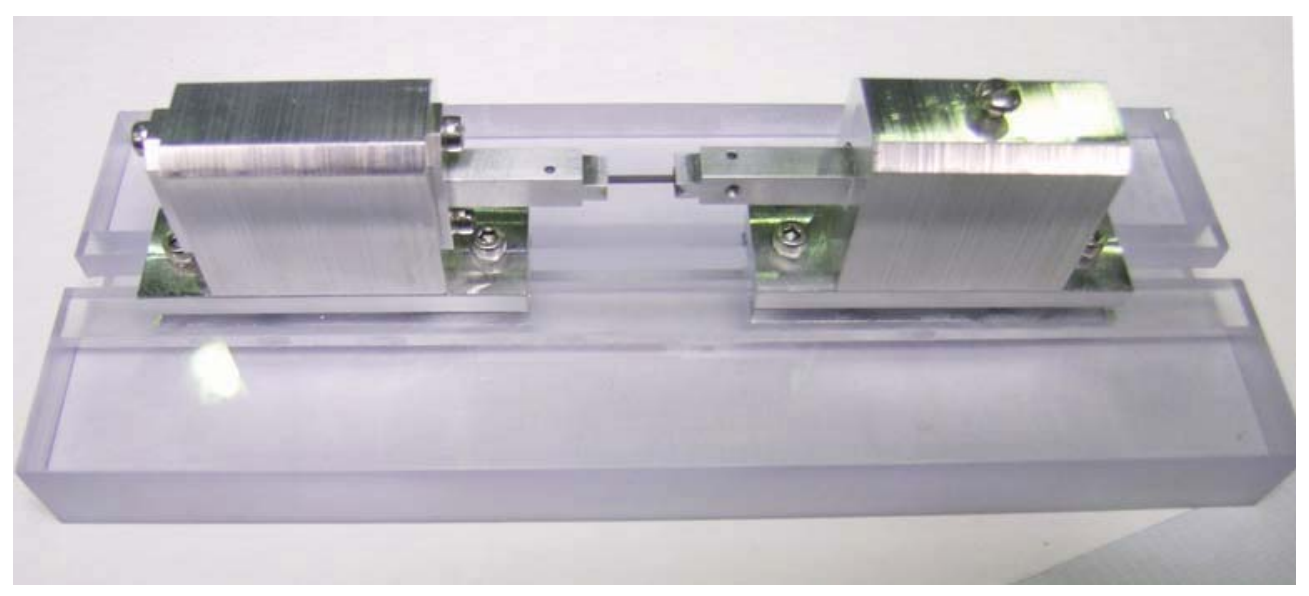

(a)

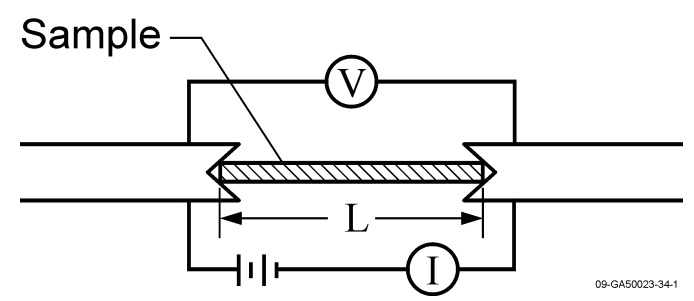

(b)

Figure 3-4. Close-up of INL fixturing for making electrical measurements. one of these factors. To further verify the suitability of the INL setup, INL/ORNL comparison evaluations of irradiated SiC temperature monitors were completed. Results from this comparison effort are documented in Section 5.

\subsubsection{Setup Verification}

INL identified several factors associated with the SiC temperature monitor evaluation process at the HTTL. This section discusses these factors and steps taken to minimize their impact.

- Sample Manufacture and Geometry - As stated in Reference 2, it is key to use SiC material provided via CVD so that the material is fully dense $\left(3.203 \mathrm{~g} / \mathrm{cm}^{3}\right)$ and stoichiometric. To meet this requirement, material certifications will be reviewed by INL prior to making $\mathrm{SiC}$ measurements.

- Sample Heatup Time - SiC monitors are isochronally heated at each annealing temperature. Consistent with practices at ORNL, INL selected an annealing time of $30 \pm 2$ minutes. It is recognized that once placed into the furnace, time is required for samples to heat to the furnace temperature. To minimize the sample heating time, the alumina crucible in which samples are placed during heating is retained within the furnace. Hence, the time required to heat the small amount of $\mathrm{SiC}$ mass is negligible.

- Furnace Thermocouple Accuracy - As noted above, evaluations were completed to assess the accuracy of the Type B thermocouple supplied in the furnace by its vendor. These evaluations were completed by inserting a Type K thermocouple, which had been calibrated with NIST traceable sources, into the furnace. As shown in Figure 3-3, measurements indicate that differences 
between the furnace and NIST-traceable thermocouple range from approximately 2 to $9{ }^{\circ} \mathrm{C}$ (depending on the furnace temperature). Hence, annealing temperatures recorded in this evaluation correspond to values indicated by the NIST-traceable thermocouple inserted in this furnace.

- Constant Temperature Chamber Equilibrium Time - After heating, SiC monitors are transferred from the furnace by placing them in a room-temperature alumina crucible (to prevent dropping and accelerate cooling) prior to placing them in the Tenney constant temperature chamber. One $\mathrm{SiC}$ monitor is placed in each of the specialized fixtures for making electrical measurements. After the constant temperature door is closed, electrical measurements are delayed by at least 30 minutes to allow the $\mathrm{SiC}$ temperature monitors to reach the constant temperature chamber temperature, which is always set at $30{ }^{\circ} \mathrm{C}$. Note that prior to making any $\mathrm{SiC}$ monitor electrical measurements, INL staff must verify that the temperature sensor in this constant temperature chamber has been calibrated within INL standards and that the calibration sticker on the chamber is current.

- Measurement Electronics Operation, Data Storage and Transfer - Tests were conducted to verify that measurement electronics were properly functioning and that measured data could be stored and transferred as needed. In addition, prior to performing any SiC monitor measurements, component calibration is verified by the INL calibration laboratory; and INL staff verifies that the power analyzer has a current calibration sticker.

- Room Temperature Unirradiated SiC Resistivity Measurements - Tests were initially conducted on 'prototype' SiC temperature monitors to verify the accuracy of the INL setup. Results from these checkout tests are reported in Section 3.2.2.

\subsubsection{Room-Temperature SiC Resistivity Measurements}

The first customer to include $\mathrm{SiC}$ temperature monitors in an ATR irradiation is the University of Wisconsin (UW). As reported in Reference 18, temperature monitors in this ATR irradiation are fabricated from SiC manufactured by Rohm and Haas. This vendor offers the three grades listed in Table 3-1.

Table 3-1. SiC grades available from Rohm and Haas.

\begin{tabular}{|c|c|c|}
\hline Description & Designator & Electrical Resistivity (ohm-cm) \\
\hline Standard Grade & SC-001 & Not provided \\
Low Grade & SC-002 & $1^{\mathrm{a}}$ \\
High Grade & SC-003 & $8323^{\mathrm{b}}$ \\
\hline
\end{tabular}

a. Low resistivity grade achieved by doping high resistivity grade with nitrogen.

b. An average value. Note that the vendor measured values for SC-003 range ranged from 2564 to 23,886 .

Temperature monitors in the UW ATR test were made from high resistivity grade (SC-003) SiC. An additional high grade sample, designated INL-1, was obtained by INL that was manufactured from the same batch of $\mathrm{SiC}$ as the ones that were inserted into the UW test capsule. In addition, UW provided INL three temperature monitor samples (labeled UW-1, UW-2, and UW-3) that were made from the same batch of $\mathrm{SiC}$ inserted into the UW test capsule and three extra temperature monitors, labeled MOCK-1, MOCK2, etc., that were made from an 'unidentified' grade of $\mathrm{SiC}$ (Rohm and Haas believed that they were made from SC-002 or SC-003). All of these prototypic high grade SiC temperature monitor samples and two of 
the MOCK samples were used to successfully verify the operation of new measurement equipment setup at the HTTL. Results are reported in Table 3-2.

Table 3-2. Initial INL SiC room temperature resistivity measurements

\begin{tabular}{|c|c|c|c|c|c|c|c|c|c|}
\hline $\begin{array}{c}\text { Sample } \\
\text { ID }\end{array}$ & $\begin{array}{c}\text { Thickness } \\
\text { (mm) }\end{array}$ & $\begin{array}{c}\text { Width } \\
(\mathrm{mm})\end{array}$ & $\begin{array}{c}\text { Length } \\
(\mathrm{mm})\end{array}$ & $\begin{array}{c}\text { Area } \\
\left(\mathrm{cm}^{2}\right)\end{array}$ & $\begin{array}{l}\text { Voltage } \\
\text { (Volts) }\end{array}$ & $\begin{array}{c}\text { Current } \\
\text { (Amps) }\end{array}$ & $\begin{array}{l}\text { Power } \\
\text { (watts) }\end{array}$ & $\begin{array}{c}\text { Resistance } \\
\text { (ohm) }\end{array}$ & $\begin{array}{c}\text { Resistivity } \\
\text { (ohm-cm }\end{array}$ \\
\hline INL-1 & 0.79 & 1.05 & 12.51 & 0.0083 & 30 & $5.97 \mathrm{E}-5$ & $1.79 \mathrm{E}-3$ & $5.03 \mathrm{E}+5$ & 3332 \\
\hline UW-1 & 0.79 & 1.02 & 12.52 & 0.0081 & 30 & $6.34 \mathrm{E}-5$ & $1.90 \mathrm{E}-3$ & $4.73 \mathrm{E}+5$ & 3045 \\
\hline UW-2 & 0.78 & 1.04 & 12.56 & 0.0081 & 30 & $6.68 \mathrm{E}-5$ & $2.00 \mathrm{E}-3$ & $4.49 \mathrm{E}+5$ & 2901 \\
\hline UW-3 & 0.79 & 1.03 & 12.56 & 0.0081 & 30 & 5.34E-5 & $1.60 \mathrm{E}-3$ & $5.62 \mathrm{E}+5$ & 3640 \\
\hline MOCK-1 & 1.70 & 1.89 & 12.84 & 0.0321 & 0.0254 & $9.00 \mathrm{E}-4$ & $2.29 \mathrm{E}-3$ & $2.82 \mathrm{E}+1$ & 0.71 \\
\hline MOCK-2 & 1.48 & 1.88 & 12.82 & 0.0278 & 0.0254 & $7.00 \mathrm{E}-4$ & $1.78 \mathrm{E}-5$ & $3.63 \mathrm{E}+1$ & 0.79 \\
\hline
\end{tabular}

In this process, voltage and current were sampled at a rate of $50 \mathrm{kHz}$ and averaged over a predefined sample period ( 1 second was selected). One averaged data point was logged for each sample period. These data were taken for 1 minute (60 sampling periods), and the resulting 60 logged data points were averaged to provide the data in the table. The voltage for each sample type was selected to preclude sample heating, but still have a measurable current.

Results indicate that the equipment in the INL setup yielded consistent values for each grade of SiC. That is, consistent resistivity values were measured for all of the SC-003 samples provided by INL and UW and all of the MOCK samples provided by UW. Furthermore, the measured values for SC-003 were within the range of values $(2,565$ and $23,886 \mathrm{ohm}-\mathrm{cm})$ provided by the vendor for this run of material. The values measured for the MOCK samples were also consistent with the $1 \mathrm{ohm}-\mathrm{cm}$ value provided by the vendor. The low values measured by INL for these MOCK samples suggest that they were made from low resistivity $\mathrm{SiC}$ (SC-002). 


\section{PROCEDURE}

Based on initial activities reported in Section 3, the following procedure was developed for conducting $\mathrm{SiC}$ temperature monitor measurements.

1. Prior to setup verify the following:

- Temperature monitors are high density $\left(3.203 \mathrm{~g} / \mathrm{cm}^{3}\right)$ CVD SiC. Review Certified Material Test Reports (CMTRs) provided by the vendor to ensure that $\mathrm{SiC}$ are made from high density material.

- $\quad \mathrm{SiC}$ monitors have been washed in a dilute hydrofluoric acid wash followed by cleaning with isopropyl alcohol (at least 70\%) and acetone (at least 99\%) to remove any organic contamination. Review SiC conformance reports to ensure that monitors received appropriate preparations prior to handling.

- SiC monitors are approximately 0.5 to $2 \mathrm{~mm} \times 0.5$ to $2 \mathrm{~mm} \times 10$ to $30 \mathrm{~mm}$ (It is recommended that samples have lengths ranging from 10 to $30 \mathrm{~mm}$ and widths and heights or diameters of approximately $1 \mathrm{~mm}$ ). Note that INL can accommodate longer length monitors, but samples must be cut or alternate fixturing or equipment is needed. Also, if the cross-sectional dimensions vary significantly, be sure to place the widest-dimension surface horizontally in the fixture (to enhance electrical contract with the fixturing).

- Calibration is current on the power analyzer module, the thermocouples inserted into the constant temperature chamber and the annealing furnace, and the purge gas flowmeter. Note that these items must either be calibrated by the INL calibration laboratory or be procured from a vendor with an ISO-17025 accreditation

- Record pertinent SiC radiation history information (peak estimated temperature, peak flux, total fluence, etc.) on traveler.

2. Set constant temperature chamber to $30.0^{\circ} \mathrm{C}$.

3. Obtain a room temperature resistivity measurement on $\mathrm{SiC}$ monitors.

4. Set furnace to desired annealing temperature (unless otherwise specified by the customer, tests will be conducted in $25{ }^{\circ} \mathrm{C}$ increments, starting at $200{ }^{\circ} \mathrm{C}$ below and until at least $50{ }^{\circ} \mathrm{C}$ above the temperature at which change in resistivity is first detected). Make sure that alumina crucible for heating $\mathrm{SiC}$ monitors is inside furnace. If annealing temperatures will ultimately exceed $400{ }^{\circ} \mathrm{C}$, purge furnace with argon gas having a minimum purity of $99.999 \%$ (corresponding with the ultrahigh purity or Grade 5 classification). To preclude SiC oxidation, the argon is provided to the furnace with a flowrate of at least 200 liters/min. for at least 30 minutes prior to inserting $\mathrm{SiC}$ monitor (Gas flow monitored using a flowmeter calibrated to INL standards).

5. When furnace thermocouple exhibits less than $1{ }^{\circ} \mathrm{C}$ variation during a 5 minute period, open furnace door and place $\mathrm{SiC}$ temperature monitors in alumina crucibles. In addition to the irradiated monitors, place a non-irradiated CVD SiC sample in the furnace to ensure accuracy in the electrical resistivity measurement and the absence of silica formation on the sample surface

6. Heat $\mathrm{SiC}$ temperature monitors for $30 \pm 2$ minutes. As noted in Section 3, sample heatup time is minimized by retaining the alumina crucibles in which samples are placed within the furnace.

7. After 30 minute annealing time is completed, open furnace and transfer $\mathrm{SiC}$ monitors to room temperature alumina crucible. If annealing temperature exceeds $400{ }^{\circ} \mathrm{C}$, turn off furnace heaters at the end of the 30 minute annealing time. To minimize sample oxidation, wait until furnace temperatures are below $400{ }^{\circ} \mathrm{C}$ before opening furnace to remove $\mathrm{SiC}$ monitors. 
8. Transfer crucible to Tenney constant temperature chamber. Place each $\mathrm{SiC}$ temperature monitor in fixturing for electrical measurements. As noted above in step 1, if the cross-sectional dimensions vary significantly, be sure to place the widest-dimension surface horizontally in the fixture (to enhance electrical contract with the fixturing). Note that all irradiated and the unirradiated $\mathrm{SiC}$ monitors are measured.

9. If additional sample annealing will be done that day, set furnace controller to next desired heating temperature.

10. Wait at least 30 minutes (to ensure that sample has reached the Tenney constant temperature chamber equilibrium temperature) prior to performing voltage and current measurements.

11. Conduct measurements at a voltage selected based on sample ohmic response. This voltage is selected to minimize sample heating and to allow a measurable current. Typically, voltage and current data are sampled at a rate of $50 \mathrm{kHz}$ and averaged over $250 \mathrm{msec}$. Log one averaged data point for each sample period. Obtain data for 15 seconds (60 sampling periods) and then average the resulting 60 logged data points. For samples with small cross sections, ensure that appropriate settings on the power analyzer are optimized for low currents (e.g., select smaller-magnitude options for current parameters).

12. After all samples in constant temperature chamber are measured, return samples to furnace for additional heating (e.g., repeat steps 4 through 11). When evaluations are complete, discard samples using laboratory procedures specified by Radcon and Waste Generator Services.

A traveler has been developed to ensure that a quality, repeatable, process is followed in making SiC temperature monitor measurements. This traveler is provided in Appendix A of this document 


\section{COMPARISON EVALUATIONS}

To verify INL's capability for detecting peak irradiation temperature, comparison evaluations were performed on SiC temperature monitors irradiated in ORNL's HFIR. In this evaluation, ORNL measurements were compared with INL measurements for identical SiC samples. Sections 5.1 and 5.2, which provide a description of the samples and the ORNL measurement results, respectively, are based on information provided by ORNL in Reference 19. Section 5.3 documents results from INL measurements. Note that this was INL's first effort to measure irradiated SiC monitors. Hence, several sensitivities, that would not typically be performed in production runs, were completed to gain additional expertise with this technique.

\subsection{Samples}

The material selected for these and all other temperature monitor applications in recent HFIR irradiations are made from high-purity, fully dense $\left(3.203 \mathrm{~g} / \mathrm{cm}^{3}\right)$ Rohm-Haas CVD SiC. ${ }^{19}$ Material was procured in plate form and ground to the desired geometry. The temperature monitors were machined in match-stick form such that the length of the bar was significantly larger than the width or thickness in order to facilitate 4-point electrical resistivity measurements. Temperature monitors were irradiated in two experiments. The first irradiation was the HFIR 18J experiment, where samples were placed in the HFIR RB position to accumulate a nominal fast neutron fluence $7 \times 10^{25} \mathrm{n} / \mathrm{m}^{2}(\mathrm{E}>0.1 \mathrm{MeV})$. These samples are listed as Sample HFIR “no-ID”, HFIR "R2", and BB2W in Table 5-1. These HFIR 18J temperature monitors were bundled together within an isothermal region of this irradiation capsule and should therefore indicate the same irradiation temperature. The second type of irradiation experiments from which temperature monitors were selected involved a series of HFIR flux trap "rabbits." In these rabbit experiments, two temperature monitors were included per rabbit in mirror positions within the capsule. Table 5-1 lists three capsules: LO 3085, LO 3090, and LO 3097. One of the "mirror" temperature monitors was retained by ORNL and measured, while the other monitor was sent to INL for measurement. As noted in Section 5.3, the 'asreceived' lengths of the three specimens from the rabbit tests were longer than values specified in Section 4. These samples were shortened to reduce scatter in data obtained with the current INL fixture.

Table 5-1. Round-robin temperature monitor measured by each laboratory

\begin{tabular}{|c|c|c|c|}
\hline \multirow{2}{*}{ Sample } & \multirow{2}{*}{ Fluence $\left(\mathbf{n} / \mathbf{m}^{\mathbf{2}}(\mathbf{E}>\mathbf{0 . 1} \mathbf{~ M e V})\right.$} & \multicolumn{2}{|c|}{ Available for Evaluation } \\
\cline { 3 - 4 } & $\sim 7 \times 10^{25}$ & ORNL & INL \\
\hline HFIR no-ID & $\sim 7 \times 10^{25}$ & $\sqrt{ }$ & \\
HFIR R2 & $\sim 7 \times 10^{25}$ & & $\sqrt{ }$ \\
HFIR BB2W & $\sim 3 \times 10^{26}$ & $\sqrt{ }$ \\
\hline LO 3085 & $\sim 3 \times 10^{26}$ & $\sqrt{ }$ & $\sqrt{ }$ \\
\hline LO 3090 & $\sim 3 \times 10^{26}$ & $\sqrt{ }$ \\
\hline LO 3097 & & & $\sqrt{ }$ \\
\hline
\end{tabular}

Prior to shipment of samples to INL or measurements at either INL or ORNL, the SiC temperature monitors were cleaned in alcohol and acetone to remove any organic contamination from the dilute hydrofluoric acid wash after irradiation. 


\subsection{ORNL Measurements}

Annealing and four-point probe electrical resistivity measurements were completed in the ORNL Low Activation Materials Development and Analysis (LAMDA) laboratory, room 274. This laboratory is temperature controlled to $72 \pm 1^{\circ} \mathrm{F}\left(22.2 \pm 0.6^{\circ} \mathrm{C}\right)$. Annealing took place in a calibrated air furnace. Samples were placed within an alumina crucible and inserted into the furnace after the furnace had come to the desired anneal temperature. Once the furnace regains the target temperature, the sample is annealed for a period of 30 minutes. Then, the sample is removed from the furnace and air-cooled. A non-irradiated CVD $\mathrm{SiC}$ sample was annealed throughout to ensure accuracy in the electrical resistivity measurement and the absence of silica formation on the sample surface. For annealing above $500{ }^{\circ} \mathrm{C}$, the temperature monitors were soaked for a period of 5 minutes in dilute hydrofluoric acid to remove silica which may have formed during the annealing process. Note that this temperature is $100{ }^{\circ} \mathrm{C}$ lower than cited in Reference 15 . Also, note that this procedure did not result in any noticeable change in the voltage reading of the non-irradiated specimen for the specimens of this study.

Prior to the first annealing, each sample was measured over a range of applied current to determine the ohmic nature of the sample. An applied current was then selected as the lower end of this ohmic range to reduce any effects of resistive heating. While the applied current was held constant for each individual sample, it was not necessarily the same for each sample.

It should be noted that ORNL fixturing and measuring process differed from the INL design. As shown in Figure 5-1, the sample is placed in a plexiglass holder with razor blades on the top and bottom portions of the fixture, or four flexible contacts. When the sample is placed within the fixture, the top is lowered to ensure contact with the four wires connected to the razor blades. ORNL selects the magnitude of the current by varying values to ensure the ohmic nature of the same (i.e., the measured voltage changes proportionally to the current). Then, a constant current value is selected such that the resistance heating of the sample is not significant. This is verified by supplying a selected current on the sample and noting whether there is a rapid change of the measured voltage in one direction. The ORNL fixturing is advantageous over the INL fixture (see Figure 3-4) because it can more easily accommodate long lengths (since measurements can be made mid-length. On the other hand, the ORNL fixture requires special care to ensure that measurements are always performed at the same location.

Figures 5-2 and 5-3 show the actual resistivity for the HFIR 18J irradiated SiC temperature monitors. In these figures, the measured voltage was converted into each material's electrical resistivity. In both monitors, the electrical resistivity was assumed to be constant below $300^{\circ} \mathrm{C}$ and was not plotted. In the range of $300-340{ }^{\circ} \mathrm{C}$, a clear change in the electrical resistivity occurs. Above $340^{\circ} \mathrm{C}$, a distinct increase in resistivity is observed for both samples. The irradiation temperature is therefore assumed to be just below this value at $320 \pm 20^{\circ} \mathrm{C}$.

Figures 5-4, 5-5 and 5-6 give the measured voltage curves for the mirror temperature monitors from LO 3085, LO 3090, and LO 3097. Sample LO3085 (Figure 5-4) indicates a very clear increase in measured voltage at $300{ }^{\circ} \mathrm{C}$ and has an ascribed irradiation temperature of $310 \pm 20^{\circ} \mathrm{C}$. Given the sharp nature of the increased measured voltage between 300 and $320^{\circ} \mathrm{C}$ for this sample, it is tempting to ascribe an even tighter error bar to this monitor. The increase in resistivity for samples LO 3090 and LO 3097 (Figures 5-5 and 5-6) are not as distinct as that of LO3085, though a convincing increase in resistivity occurs at a temperature of $672 \pm 20^{\circ} \mathrm{C}$. 

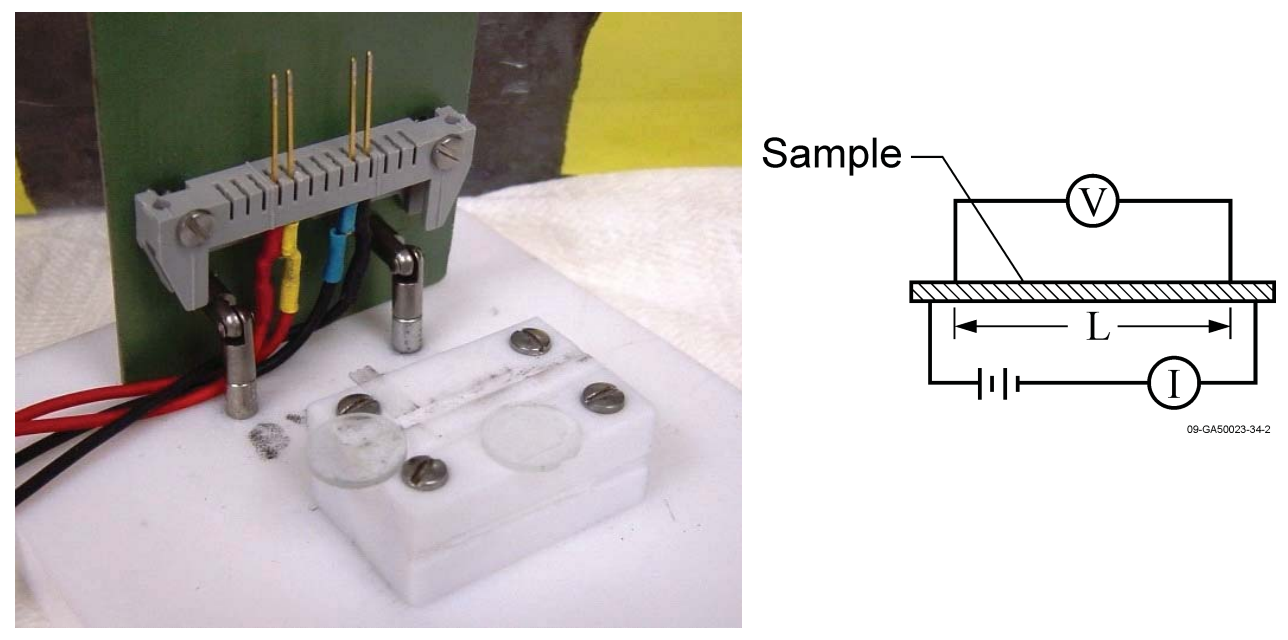

Figure 5-1. ORNL fixturing for electrical measurements.

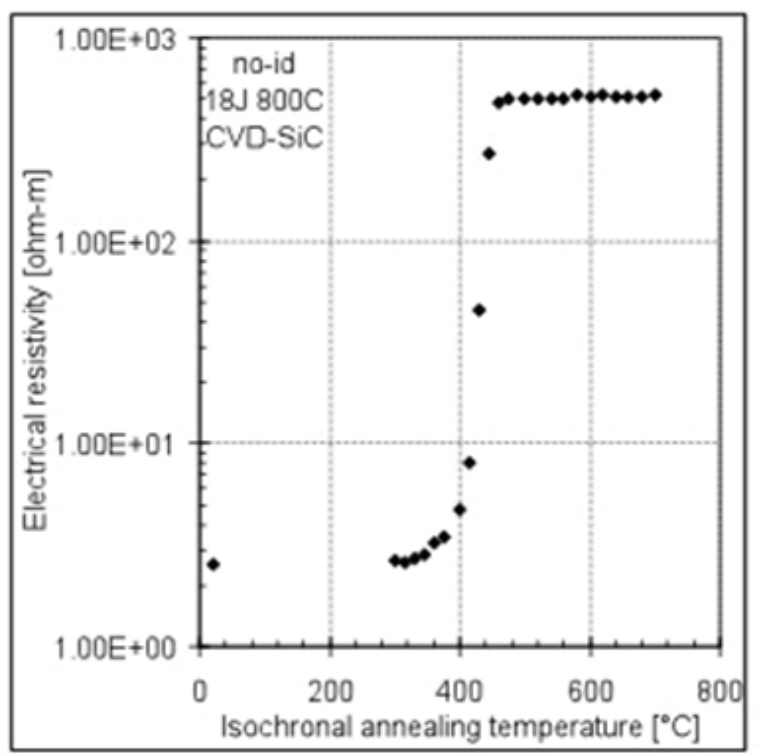

Figure 5-2. Electrical resistivity of the 18J SiC temperature monitor "no ID" (resistivity values calculated by ORNL from measured voltage and constant current).

In summary, these measurements indicate that the samples being utilized for this study behave as expected for $\mathrm{SiC}$ temperature monitors utilized for ORNL irradiation experiments. 


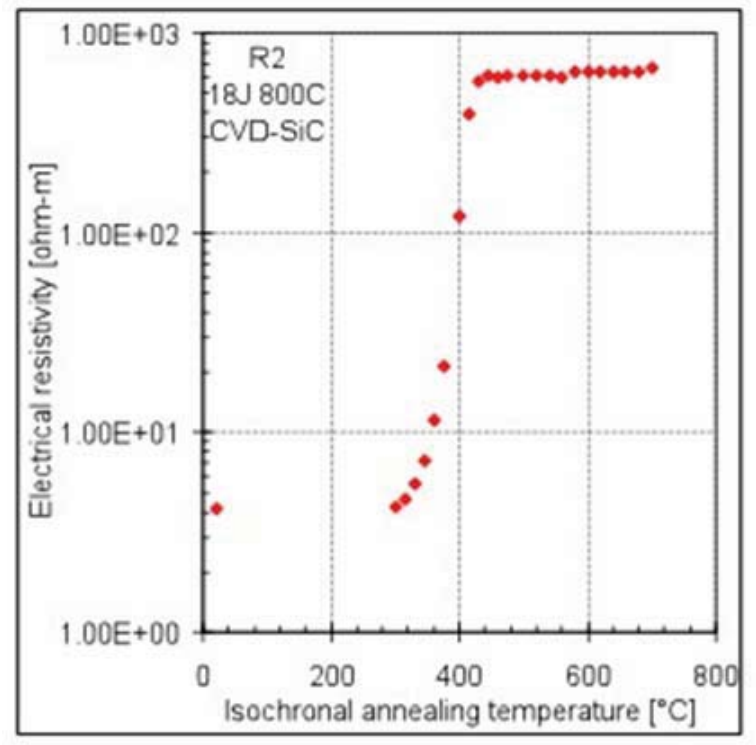

Figure 5-3. Electrical resistivity of the $18 \mathrm{~J} \mathrm{SiC}$ temperature monitor "R2"(resistivity values calculated by ORNL from measured voltage and constant current)

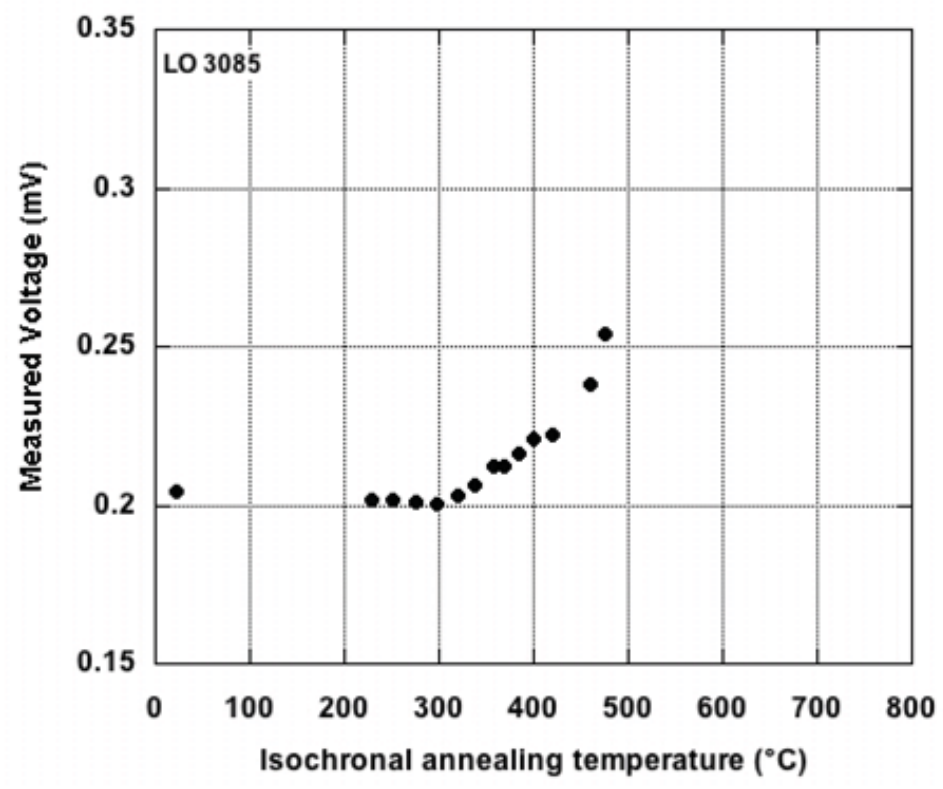

Figure 5-4. Measured voltage for the LO 3085 mirror temperature monitor (obtained by ORNL with constant current). 


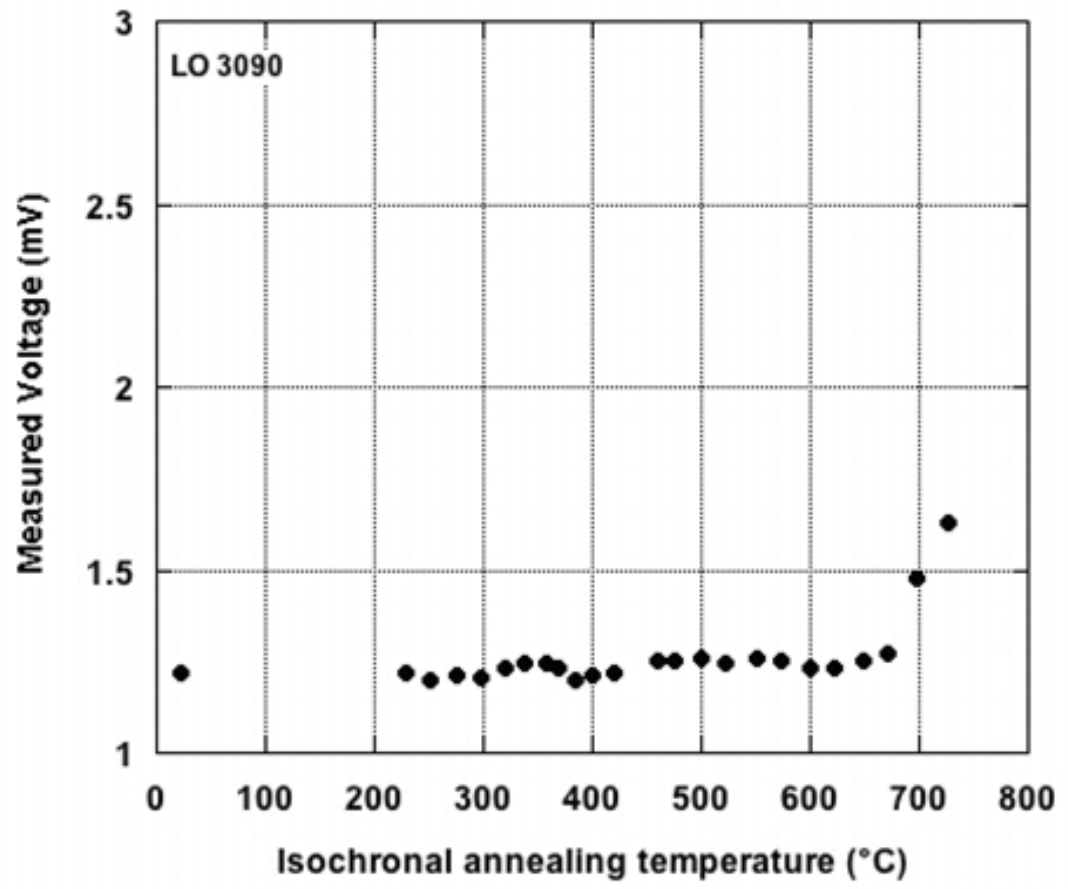

Figure 5-5. Measured voltage for the LO 3090 mirror temperature monitor (obtained by ORNL with constant current).

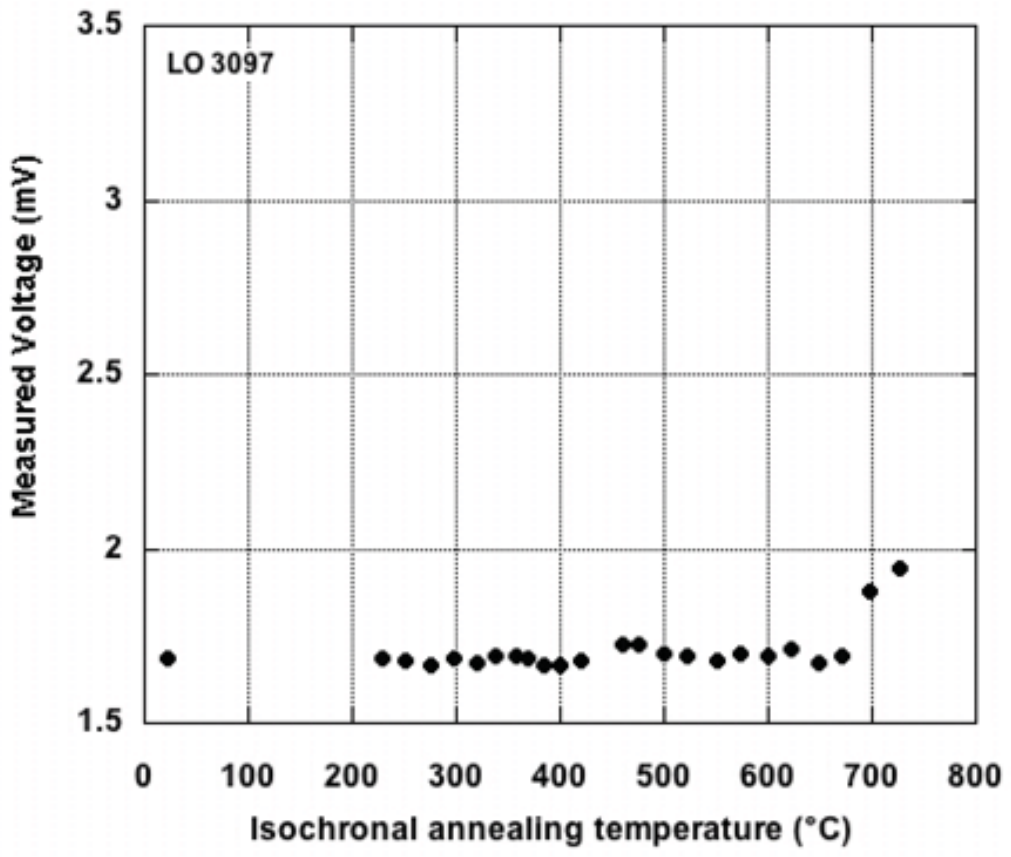

Figure 5-6. Measured voltage for the LO 3097 mirror temperature monitor 


\subsection{INL Measurements}

Annealing and four-point probe electrical resistivity measurements at INL are carried out in the HTTL using the equipment and procedure outline in Sections 3 and 4. For these initial measurements, there was a procedure deviation because no standard was available to include in the annealing/resistance measurement steps. In addition, as noted in this section, as INL gained experience in this process, additional steps were developed that are now included in the procedure. Appendix A contains a representative traveler that will be used in $\mathrm{SiC}$ production measurements.

Table 5-2 summarizes characteristics of the samples measured by INL. The three rabbit samples received from ORNL (e.g., LO 3085, LO 3090, and LO 3097) were significantly longer with smaller heights than specified in Section 4. Because INL fixturing could accommodate the 'as-received' lengths and heights of these specimens, an effort was initially made to measure the resistivity of the entire length of one of these specimens, the LO 3085 sample. As discussed in this section, initial efforts to measure this long thin sample were unsuccessful due to excessive scatter in the data. In an effort to reduce the scatter, longer samples were cut to $25 \mathrm{~mm}$ or shorter lengths. Note that the cutting process was difficult due to sample breakage. In fact, samples L03085 and L03090 were less than $25 \mathrm{~mm}$ in length after cutting. However, even after cutting these samples, significant scatter continued to be observed in the data. Ultimately, this data scatter was reduced by modifying settings on the power analyzer so that its accuracy was optimized for very small currents (see step 11 of Section 4).

Table 5-2. Samples measured by INL

\begin{tabular}{|l|c|c|c|c|}
\hline \multirow{2}{*}{\multicolumn{1}{|c|}{ Sample }} & \multirow{2}{*}{$\begin{array}{c}\text { Fluence }\left(\mathbf{n} / \mathbf{m}^{2}\right. \\
(\mathbf{E}>\mathbf{0 . 1} \mathbf{~ M e V})\end{array}$} & Length & Width & Height \\
\cline { 3 - 5 } & $\sim 7 \times 10^{25}$ & 25.51 & 2.00 & 1.50 \\
\hline HFIR BB2W & $\sim 3 \times 10^{26}$ & 45.36 & 0.97 & 0.46 \\
\hline LO 3085- as received $^{\mathrm{a}}$ & & 18.46 & 0.97 & 0.46 \\
LO 3085 -after cutting & & 16.55 & 0.96 & 0.46 \\
\hline LO 3090 & $\sim 3 \times 10^{26}$ & 25.01 & 0.98 & 0.43 \\
\hline LO 3097 & $\sim 3 \times 10^{26}$ & & & \\
\hline
\end{tabular}

a. As-received length.

b. Sample cut from as-received length.

Figure 5-7 shows INL resistivities obtained for the BB2W sample from the HFIR 18J test. As shown in this figure, the electrical resistivity did not significantly increase for measurements taken at temperatures below $300{ }^{\circ} \mathrm{C}$. However, in the range between 300 and $325^{\circ} \mathrm{C}$, the electrical resistivity increases dramatically. Hence, the irradiation temperature is therefore assumed to be below this value, $313 \pm 13{ }^{\circ} \mathrm{C}$, which is within the ORNL-estimated value of $320 \pm 20^{\circ} \mathrm{C}$. Actual resistivities obtained by INL differ significantly from values measured by ORNL for the $18 \mathrm{~J}$ test. As discussed in this document, the actual resistivity is a function of the sample geometry, selected current, and voltage. Hence, measurement results are compared by plotting "relative resistivities." as shown in Section 5.4. 


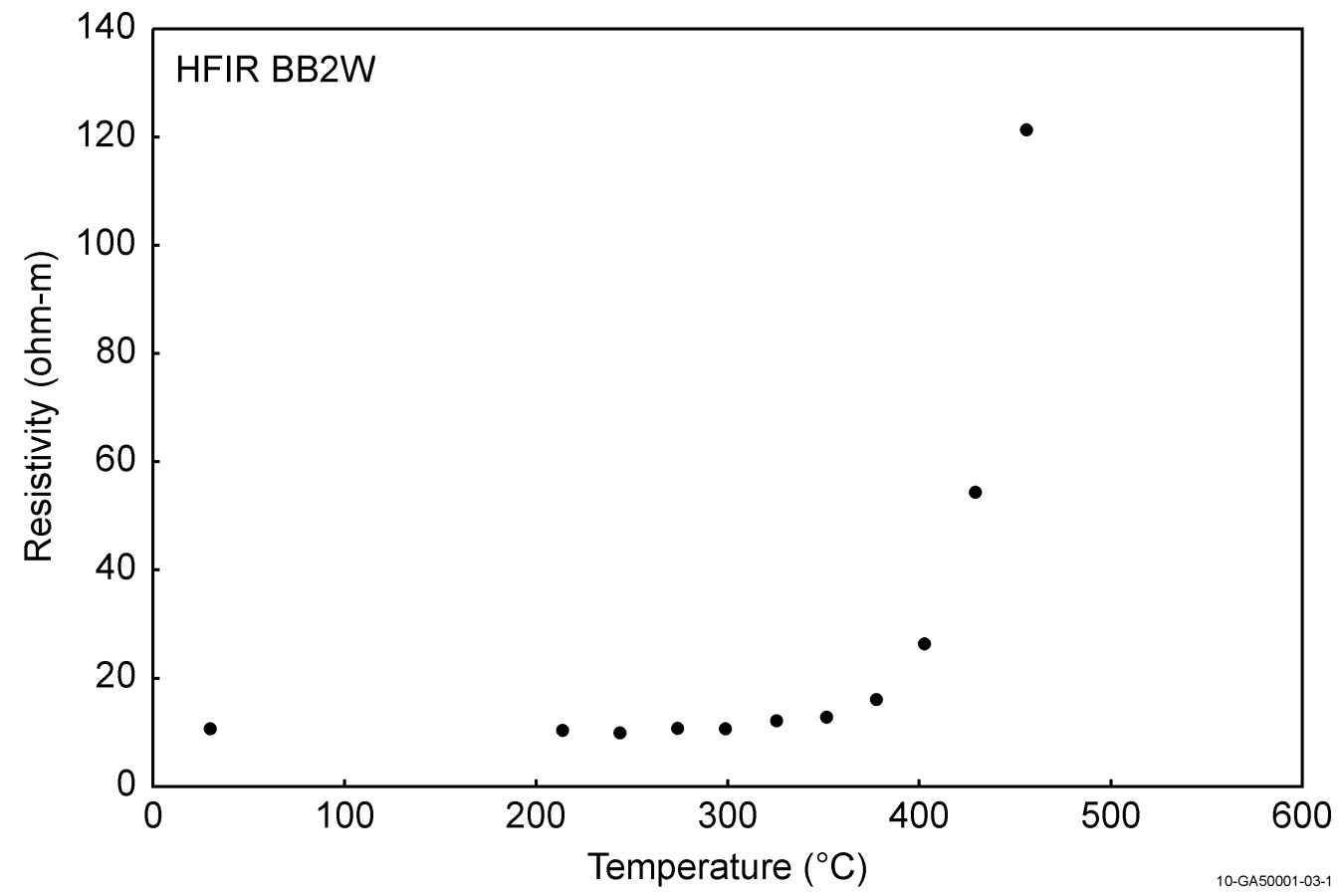

Figure 5-7. Electrical resistivity of the $18 \mathrm{~J} \mathrm{SiC}$ temperature monitor "HFIR BB2W."

The LO 3085 sample was next evaluated. As discussed above, the as-received length of this sample was nearly twice the anticipated length for SiC monitors. In addition, this sample's cross sectional area was considerably smaller. Although results for the full length LO 3085 sample did suggest some increase in resistivity at temperatures above $300{ }^{\circ} \mathrm{C}$, the scatter in the obtained data was too large to determine a peak irradiation temperature. Initially, it was suspected that current values were too low because of the 'asreceived' sample length. After the measurement at $388^{\circ} \mathrm{C}$ was completed, the sample was shortened. Although measured resistivity values continued to show an upward trend, the scatter in measured data was still significant.

Electrical resistivity results for the LO 3090 sample are plotted in Figure 5-8. Based on experience with LO 3085, the length of this sample was shortened prior to testing. However, low temperature data obtained from this sample, which also had a fairly small cross-sectional area, still exhibited too much scatter. After annealing the sample at $597.5^{\circ} \mathrm{C}$, the settings on the power analyzer were modified such that it was optimized for obtaining low current data (see Step 11 of Section 4). As shown in Figure 5-8, the scatter in data obtained at higher temperatures was significantly reduced. However, resistivity values obtained at temperatures at and above $623.9^{\circ} \mathrm{C}$ were significantly higher, suggesting that changes in the power analyzer setting affected results. Subsequent data suggest that resistivity increased after the $648.7^{\circ} \mathrm{C}$ anneal. The cause for the decreased value for resistivity after the $699^{\circ} \mathrm{C}$ anneal is not clear. However, discussions with Snead $^{20}$ indicate that such behavior is often seen at higher temperatures, due to annealing of complex defects. It should also be noted that similar decreases were observed in results for LO 3097.

Figure 5-9 shows resistivity data obtained for the LO 3097 sample. Note that this sample was also shortened prior to evaluations. In addition, the power analyzer settings were optimized for obtaining low current measurements prior to evaluating this sample. As shown in this figure, the resistivity measurements were considerably more stable than data obtained for either the LO 3085 or LO 3097 monitors. Data in this plot suggest that peak irradiation temperature for this sample is $625 \pm 13{ }^{\circ} \mathrm{C}$. It is interesting to note that 


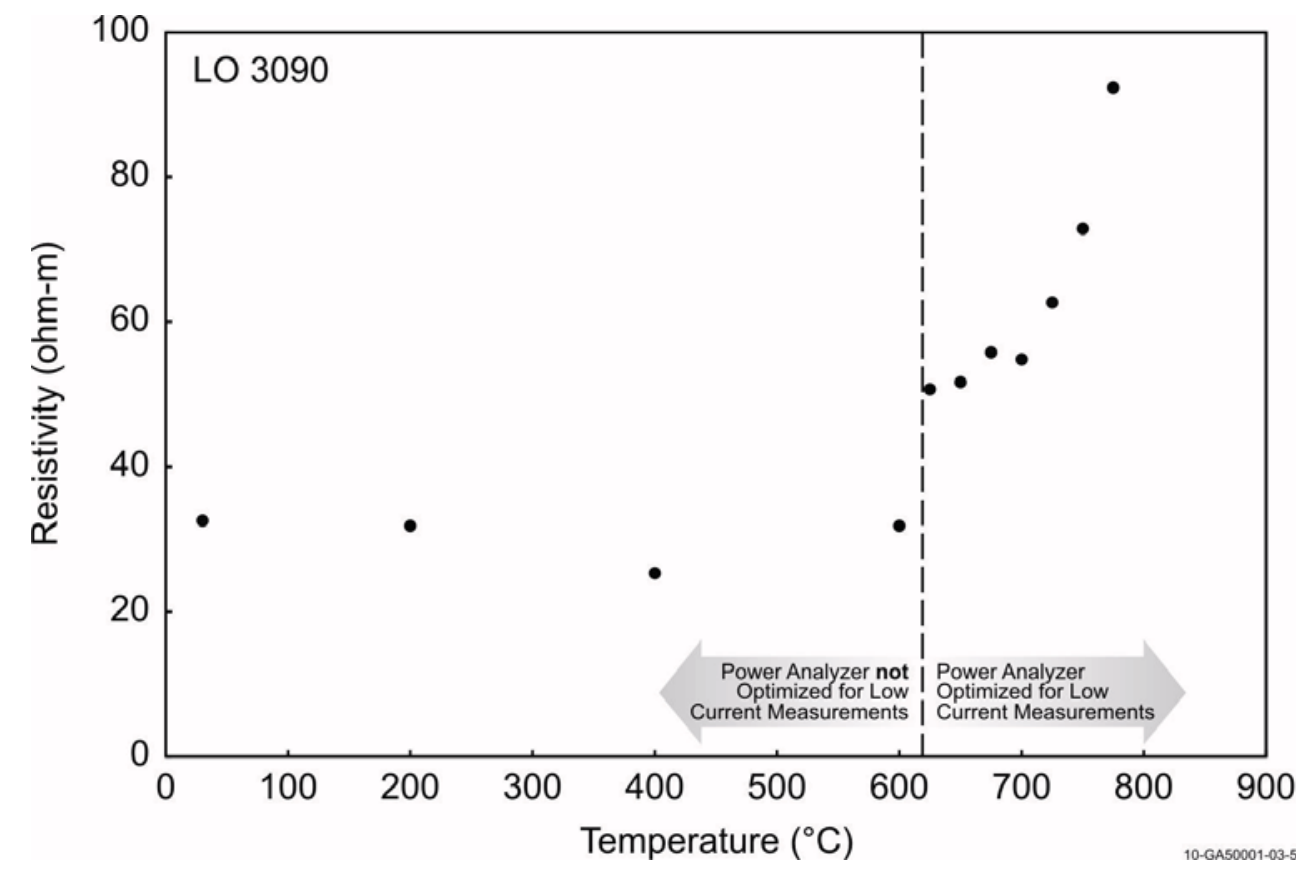

Figure 5-8. Electrical resistivity for the LO 3090 mirror temperature monitor.

resistivity data taken at and above temperatures of $675{ }^{\circ} \mathrm{C}$ were similar. As previously noted, discussions with Snead $^{20}$ indicate that such behavior is often seen at higher temperatures, due to complex defect annealing.

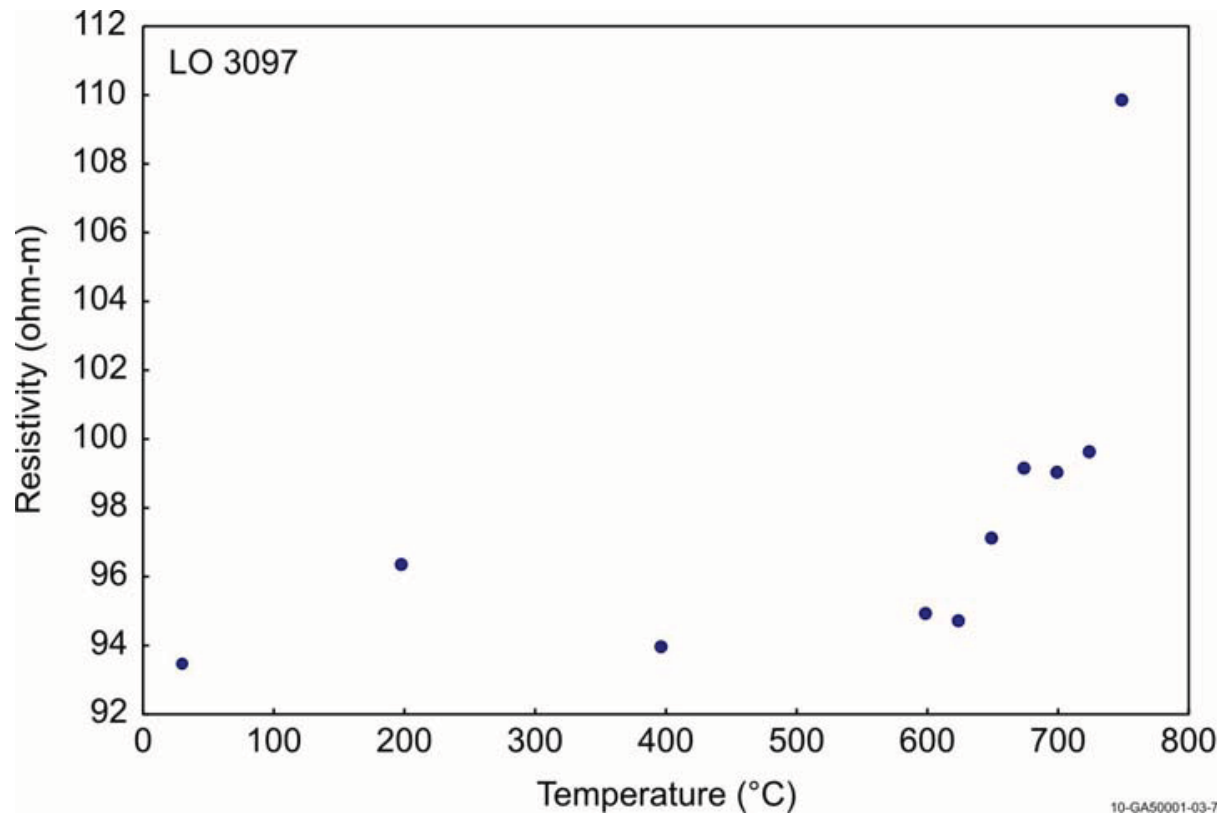

Figure 5-9. Electrical resistivity for the LO 3097 mirror temperature monitor 


\subsection{Summary and Recommendations}

Table 5-3 summarizes results obtained by ORNL and INL for these SiC temperature monitors. In general, temperatures estimated by each laboratory were similar. It should be noted that INL was developing a new capability as they completed these comparison measurements. During this process, INL learned that obtaining data with the INL fixture was more difficult for longer samples with small cross sections. Hence, no peak temperature could be designated by INL for sample LO 3085.

Table 5-3. Round-robin temperature monitor results

\begin{tabular}{|c|c|c|c|c|}
\hline \multicolumn{2}{|c|}{ Test / Sample } & Fluence $\left(\mathbf{n} / \mathbf{m}^{\mathbf{2}} \mathbf{( E > 0 . 1} \mathbf{M e V}\right)$ & \multicolumn{2}{c|}{ Measured Temperature, ${ }^{\circ} \mathbf{C}$} \\
\cline { 3 - 5 } & & ORNL & INL \\
\hline 18J & HFIR no-ID & $\sim 7 \times 10^{25}$ & $320 \pm 20$ & - \\
& HFIR R2 & & $320 \pm 20$ & $313 \pm 13$ \\
\hline LO & HFIR BB2W & & - & $>300^{\mathrm{a}}$ \\
& LO 3085 & $\sim 3 \times 10^{26}$ & $310 \pm 20$ & $650 \pm 13$ \\
& LO 3090 & $\sim 3 \times 10^{26}$ & $672 \pm 20$ & $625 \pm 13$ \\
\hline
\end{tabular}

a. This was INL's first attempt to work with a small cross-sectional area and long initial length sample. Because the small cross-sectional dimensions and long initial length for this sample made data obtained for this samples suspect, they are not presented.

Figures 5-10 through 5-12 compare relative resistivities obtained by ORNL for the three remaining samples. Results indicate that relative resistivities increase at similar temperatures for each sample.

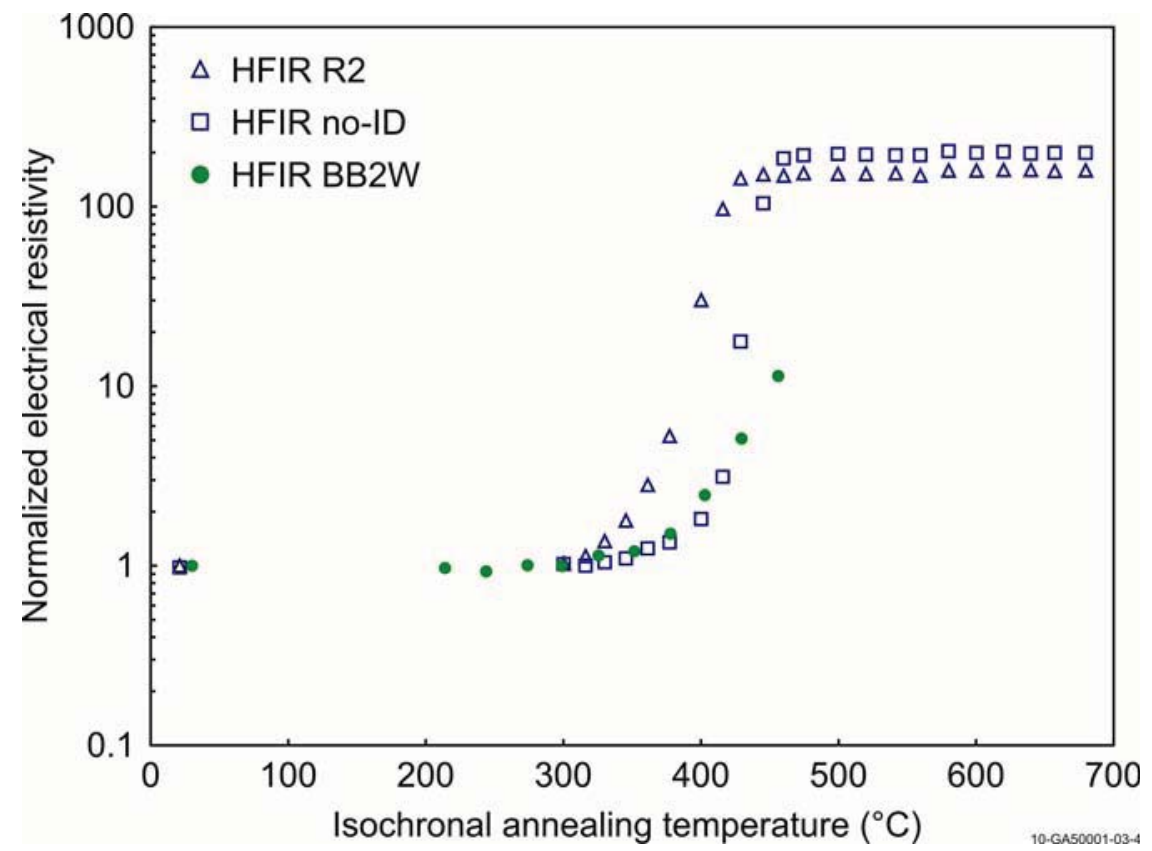

Figure 5-10. Comparison of results obtained by INL (HFIR BB2W) and ORNL (HFIR R2 and no-ID) for samples heated in the $18 \mathrm{~J}$ test. 


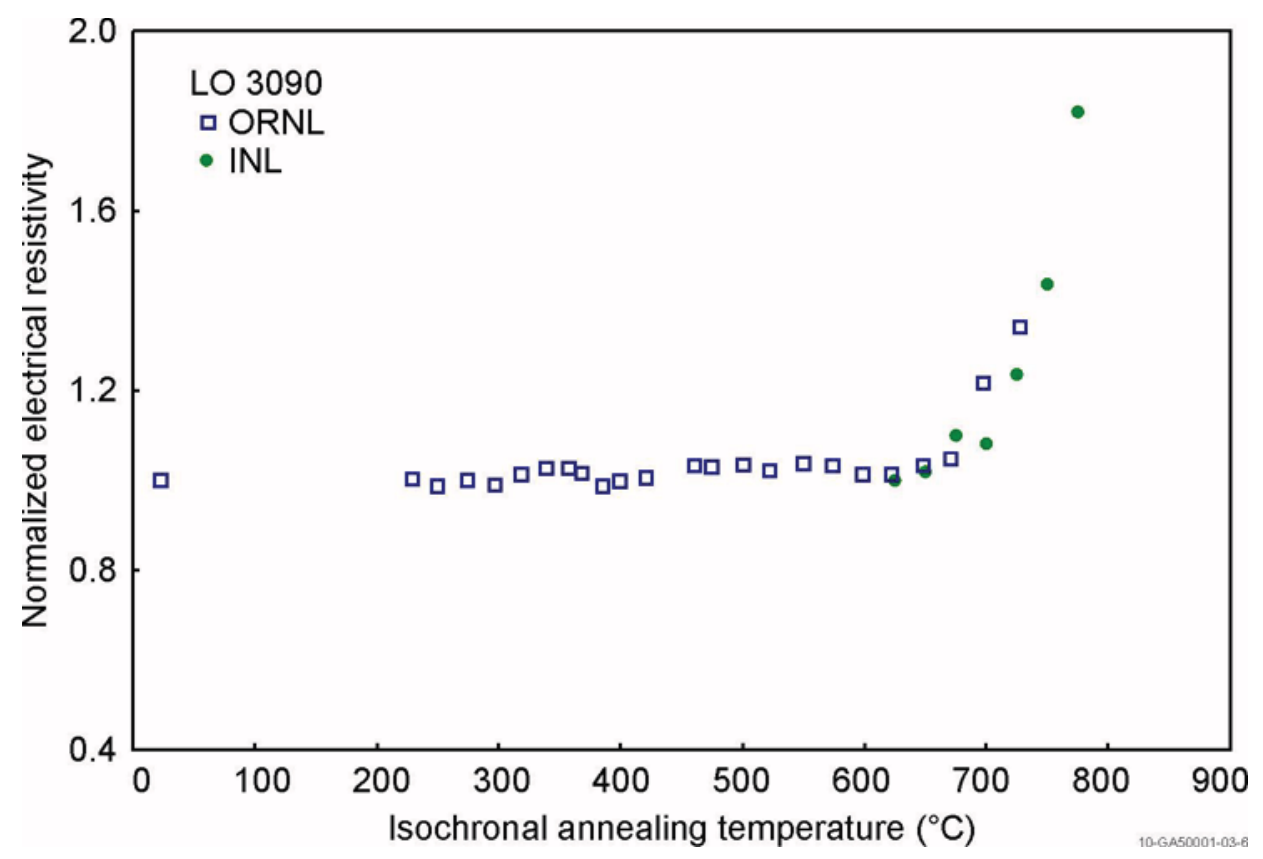

Figure 5-11. Comparison of INL and ORNL results for L03090 (INL data only included after power analyzer settings were optimized for low current measurements).

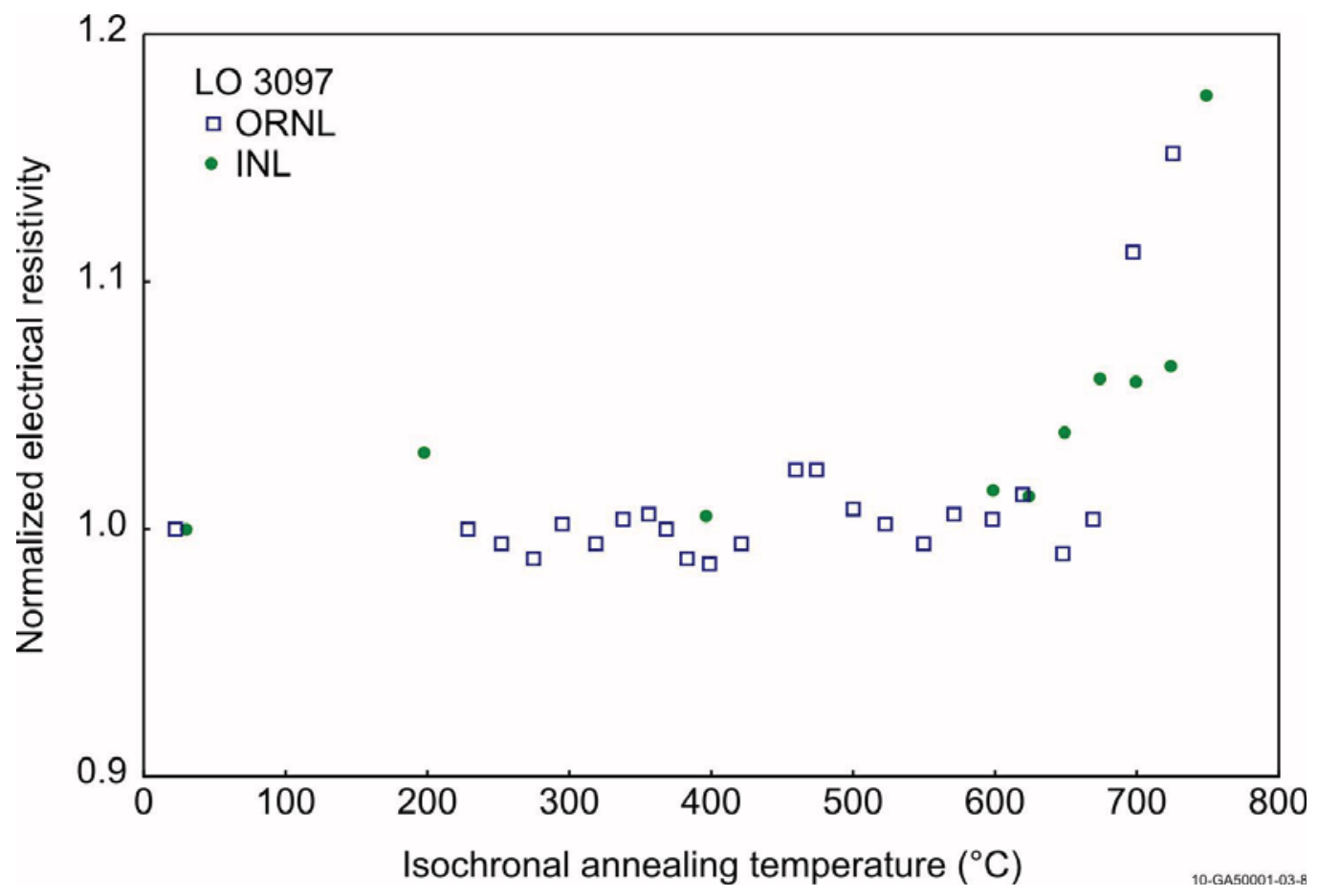

Figure 5-12. Comparison of INL and ORNL results for L03097. 


\section{INSIGHTS AND RECOMMENDATIONS}

As part of the process initiated by the ATR National Scientific User Facility (NSUF) to make SiC temperature monitors available to ATR customers, a capability has been developed to complete post-irradiation evaluations of these monitors at the High Temperature Test Laboratory (HTTL) of the Idaho National Laboratory (INL). As discussed within this document, a resistance measurement approach for determining irradiation temperature from $\mathrm{SiC}$ temperature monitors was implemented at INL. This approach was selected because of recent successes by Oak Ridge National Laboratory (ORNL) in determining irradiation temperature. ${ }^{2}$ To develop and ultimately demonstrate INL capabilities in this approach, comparison measurements were performed by INL and ORNL on identical irradiated SiC samples.

As shown in Figures 6-1 through 6-3, INL's capability to evaluate peak irradiation temperature yielded peak irradiation temperatures that were similar to values obtained by ORNL. In Figure 6-1, resistivity values measured for all three samples increase above around $300^{\circ} \mathrm{C}$, indicating peak irradiation temperatures between $313-320^{\circ} \mathrm{C}$ (see Table 6-1). The $18 \mathrm{~J}$ test samples had much larger cross-sectional dimensions than the LO samples (see Table 6-1). As discussed in this document, INL initially experienced some difficulty in obtaining accurate measurements from such long (e.g., greater than $25 \mathrm{~mm}$ ) thin (e.g., less than 1 $\mathrm{mm}$ ) LO samples. However, once these sample lengths were shortened and the power analyzer settings were optimized for obtaining precise low current measurements, the scatter in data obtained from thin samples was reduced. As shown in Figures 6-2 and 6-3, ORNL and INL observed resistivity values to increase at similar temperatures.

Table 6-1. Round-robin temperature monitor summary results

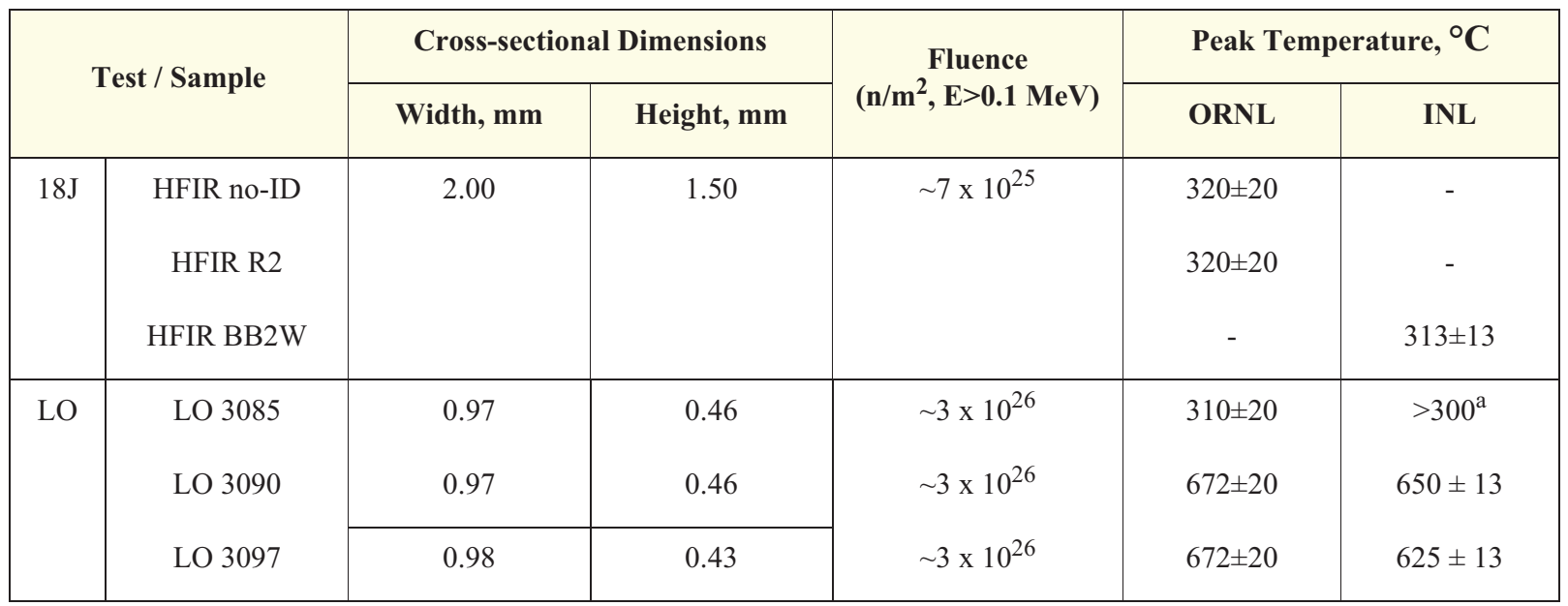

a. Because the small cross-sectional dimensions and long initial length for this sample made data obtained for this samples suspect, they are not presented.

In summary, results from these comparisons provided INL valuable experience with determining irradiation temperature data from irradiated specimens. Based on insights gained from these comparison measurements and previous evaluations from ORNL, the following recommendations should be considered in evaluations of $\mathrm{SiC}$ temperature monitors: 


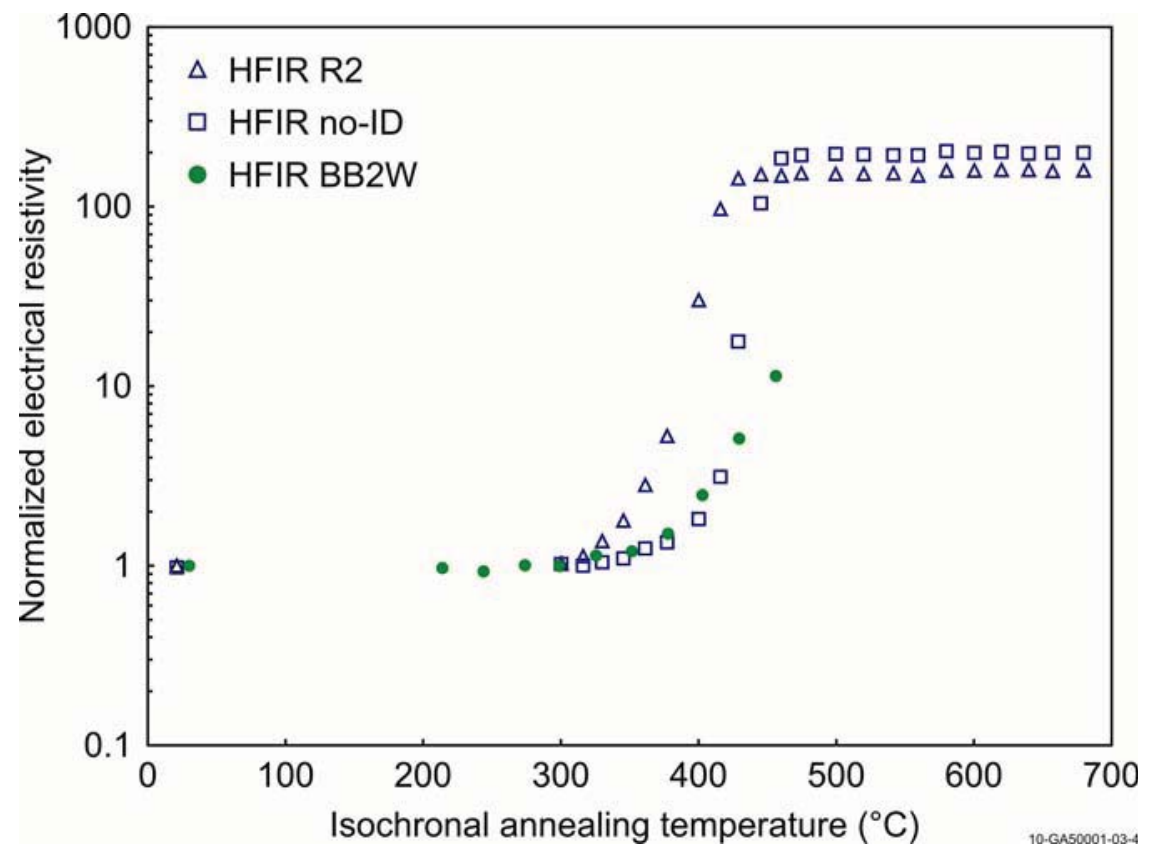

Figure 6-1. Comparison of INL (BB2W) and ORNL (R2 and no-ID) results for samples heated in the $18 \mathrm{~J}$ test.

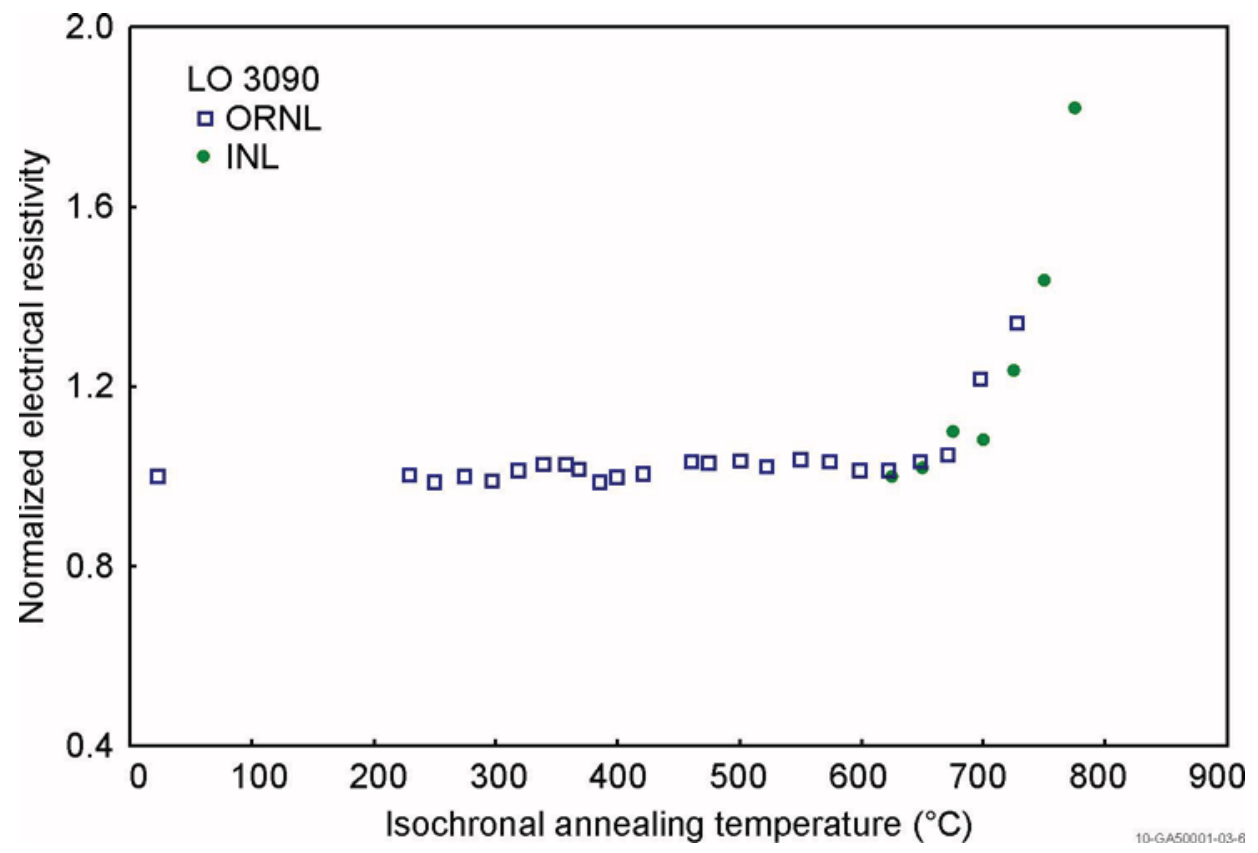

Figure 6-2. Comparison of INL and ORNL results for LO 3090 samples (INL data only included after power analyzer settings were optimized for low current measurements). 


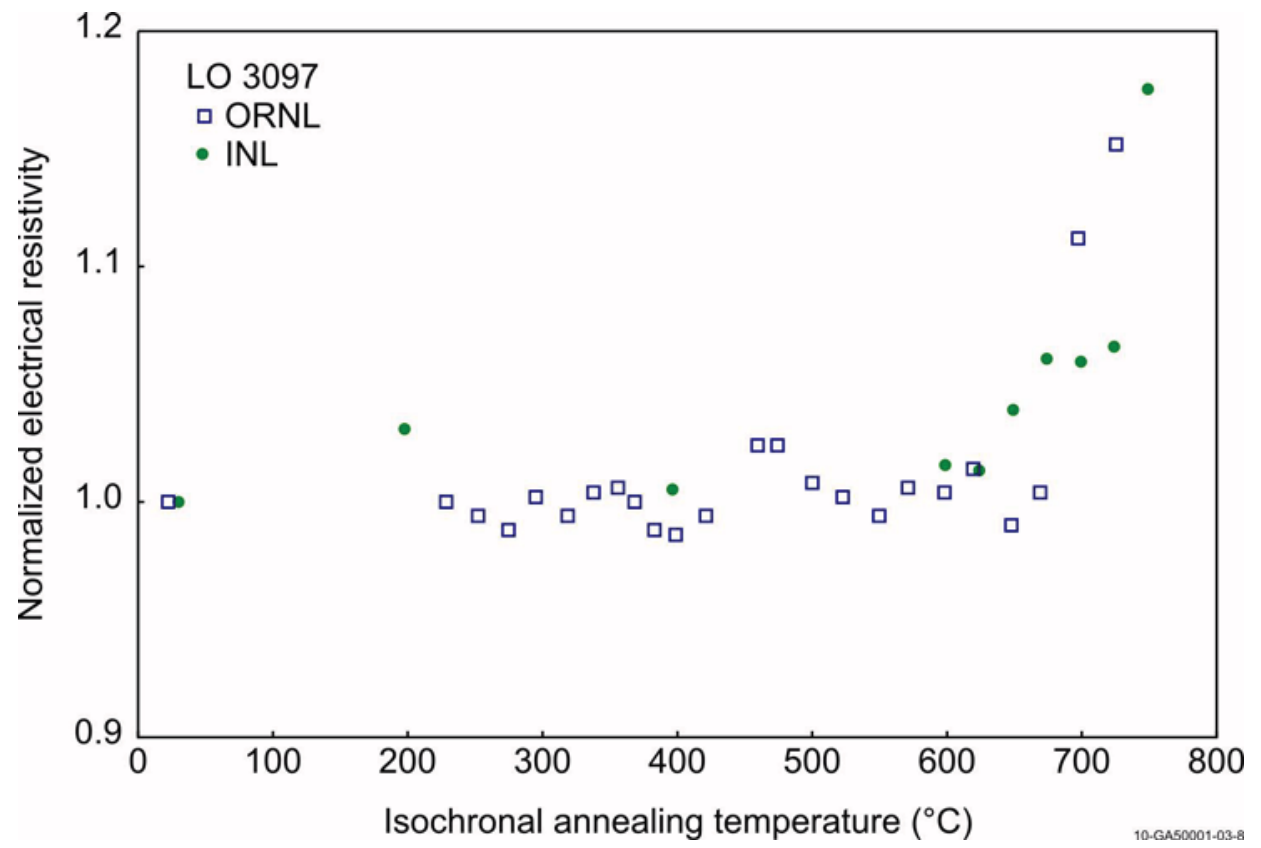

Figure 6-3. Comparison of INL and ORNL results for LO 3097 samples.

- Ensure that monitors are fabricated from fully dense $\left(3.203 \mathrm{~g} / \mathrm{cm}^{3}\right)$ and stoichiometric SiC.

- Lengths of SiC monitors should range between 10 and $30 \mathrm{~mm}$. Thicknesses and heights of at least $1 \mathrm{~mm}$ are recommended if rectangular cross sections are selected, or diameters of at least $1 \mathrm{~mm}$ are recommended if circular cross sections are selected.

- Settings for the power analyzer should be optimized for low current measurements. The scatter in the data can adversely impact the accuracy of peak irradiation temperature evaluations, especially if thinner specimens are being evaluated.

- Annealing temperatures should be detected with thermocouples that have been calibrated with NIST-traceable references, rather than relying upon furnace thermocouples.

- Annealing in a tube furnace purged with ultra-high purity argon gas appears to preclude silica formation at temperatures up to at least $775^{\circ} \mathrm{C}$ (although future evaluations should include an unirradiated $\mathrm{SiC}$ monitor to verify this point). Note that after annealing, monitors should be left in an unopened furnace until its internal temperature is significantly lower (as indicated in the INL procure, temperatures were below $400{ }^{\circ} \mathrm{C}$ prior to opening the furnace to remove a monitor).

As noted in Section 3 of this document, these insights and recommendations were implemented during this effort and are included in the procedure developed for future $\mathrm{SiC}$ temperature monitor evaluations. 
INL/EXT-10-17608 


\section{REFERENCES}

1. N. F. Pravdyuk, V. A. Nikolaenko, V. I. Kapuchin, V.N. Kusnetsov, in: Ed. D. J. Littler, Proceedings of the Properties of Reactor Materials and the Effects of Radiation Damage, Butterworths, 1962, p. 57.

2. L L. Snead, A. M. Williams, and A. L. Qualls, "Revisiting the use of SiC as a Post Irradiation Temperature Monitor," Effects of Radiation on Materials, ASTM STP 1447, M L. Grossbeck, Ed, ASTM International, West Conshohocken, PA, 2003.

3. M. Balarin, "Zür Temperaturabhangigkeit der Strahlensattigung in SiC," Physica Status Solidi, 11, Issue 1, (1965), K67.

4. H. Huang and N. Ghoniem, "A Swelling Model for Stoichiometric SiC at Temperatures below 1000 degrees C under Neutron Irradiation," Journal of Nuclear Materials, 250, Issues 2-3, (December 1997), p. 192.

5. R.P. Thorne and V.C. Howard, "Changes induced in Polycrystalline Alumina by Fast Neutron Irradiation," Proceedings of the British Ceramics Society, 7 (Feb. 1967), p. 439-448.

6. R. Blackstone and E.H. Voice, "Expansion of Silicon Carbide by Neutron Irradiation at High Temperature," Journal of Nuclear Materials, 39, Issue 3, (1971) 319.

7. R.J. Price, Thermal-Conductivity of Neutron-Irradiated Pyrolytic Beta-Silicon Carbide, J. Nucl. Mat. 46, Issue 3 (1973) p. 268-272.

8. H. Miyazaki, T. Suzuki, T. Yano, and T. Iseki, "Effects of Thermal Annealing on the Macroscopic Dimension and Lattice-Parameter of Heavily Neutron-Irradiated Silicon Carbide," Journal of Nuclear Science and Technology, 29, Issue 7 (July 1992), 656-663.

9. H. Suzuki, T. Iseki, and M. Ito, “Annealing Behavior of Neutron-Irradiated Beta-SiC," Journal of Nuclear Materials, 48, Issue 3 (1973), 247.

10. R.J. Price, "Annealing Behavior of Neutron-Irradiated Silicon-Carbide Temperature Monitors," Nuclear Technology, 16, Issue 3, (1972) p. 536.

11. J.E. Palentine, "Development of Silicon-Carbide as a Routine Irradiation Temperature Monitor and its Calibration in a Thermal Reactor," Journal of Nuclear Materials, 61, Issue 3 (1976) p. 243-253.

12. T. Maruyama, and S. Onose, "Determination of Irradiation Temperature Using SiC Temperature Monitors," presented at the Third JAEIR-KAERI Joint Seminar on Irradiation Examination Technology, JAERI-Conf 99-009, 1999 p. 335-340.

13. L. Snead, "Revisiting the use of $\mathrm{SiC}$ as a Post Irradiation Temperature Monitor," Presented at the International Symposium on Materials Test Reactors, Idaho Falls, ID, September 28, 2009.

14. J.I. Bramman and A.S. Frazer, W.H. Martin, J. Nuclear Energy, 25 (1971) 223.

15. L. Snead, ORNL, email to J. Rempe, INL, dated July 31, 2008. 
16. L. L. Snead, ORNL, email to J. Rempe, INL, dated August 28, 2009.

17. L. Snead, ORNL, email to J. Rempe, INL, dated October 15, 2009.

18. K. Sridharan, UW-Madison, letter to J. Rempe, INL, dated February 17, 2009. Letter attachment includes 4 point probe measured values provided by R. Baren, Rohm and Haas, taken February 2, 2008 for SiC from Run 9214-H-6.

19. L. L. Snead, "Round Robin Testing of HFIR Irradiated SiC Temperature Monitors," ORNL Letter Report, dated October 23, 2009.

20. L.L. Snead, ORNL, discussions with J. Rempe, January 2010. 
APPENDIX A - SAMPLE SiC TRAVELER 


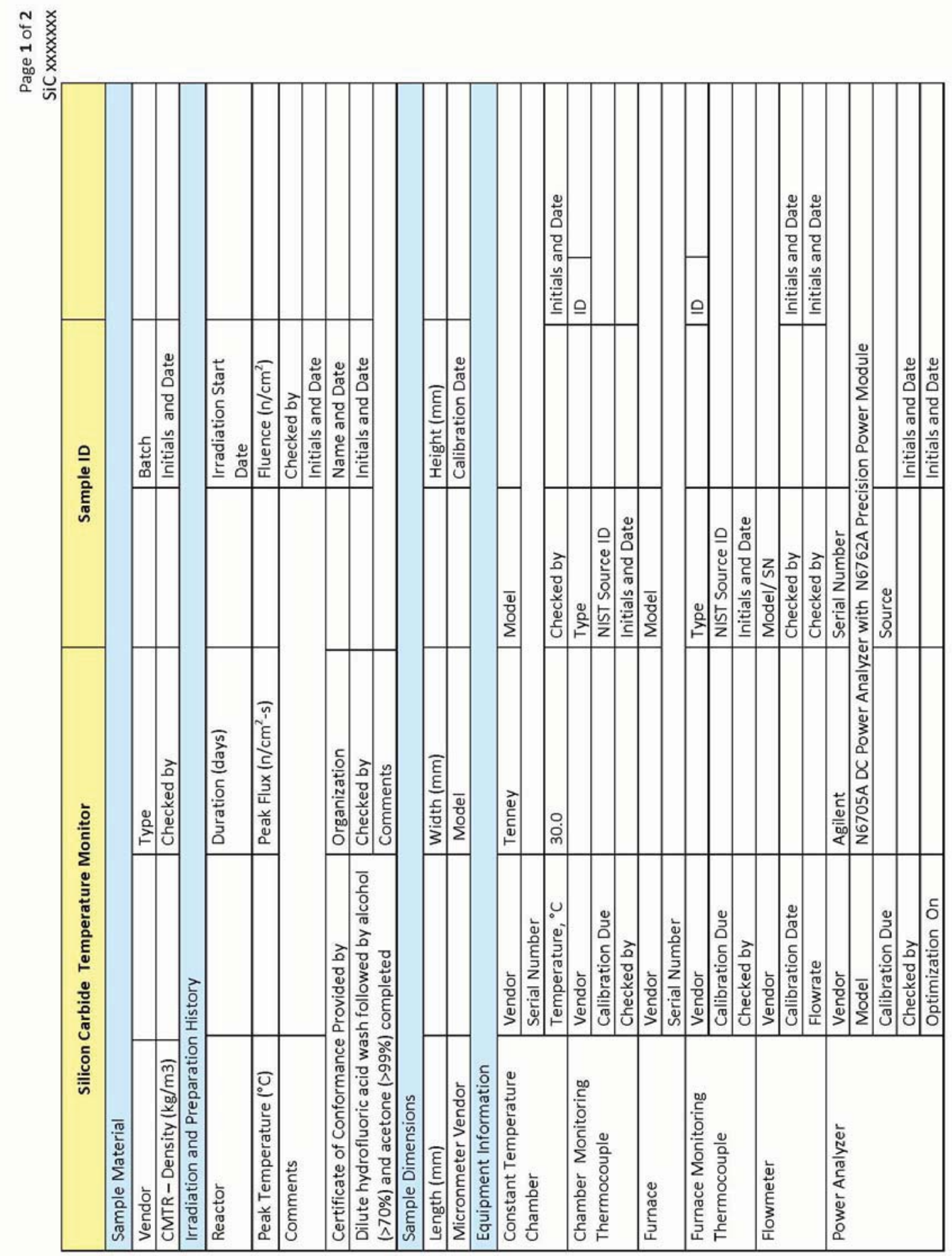




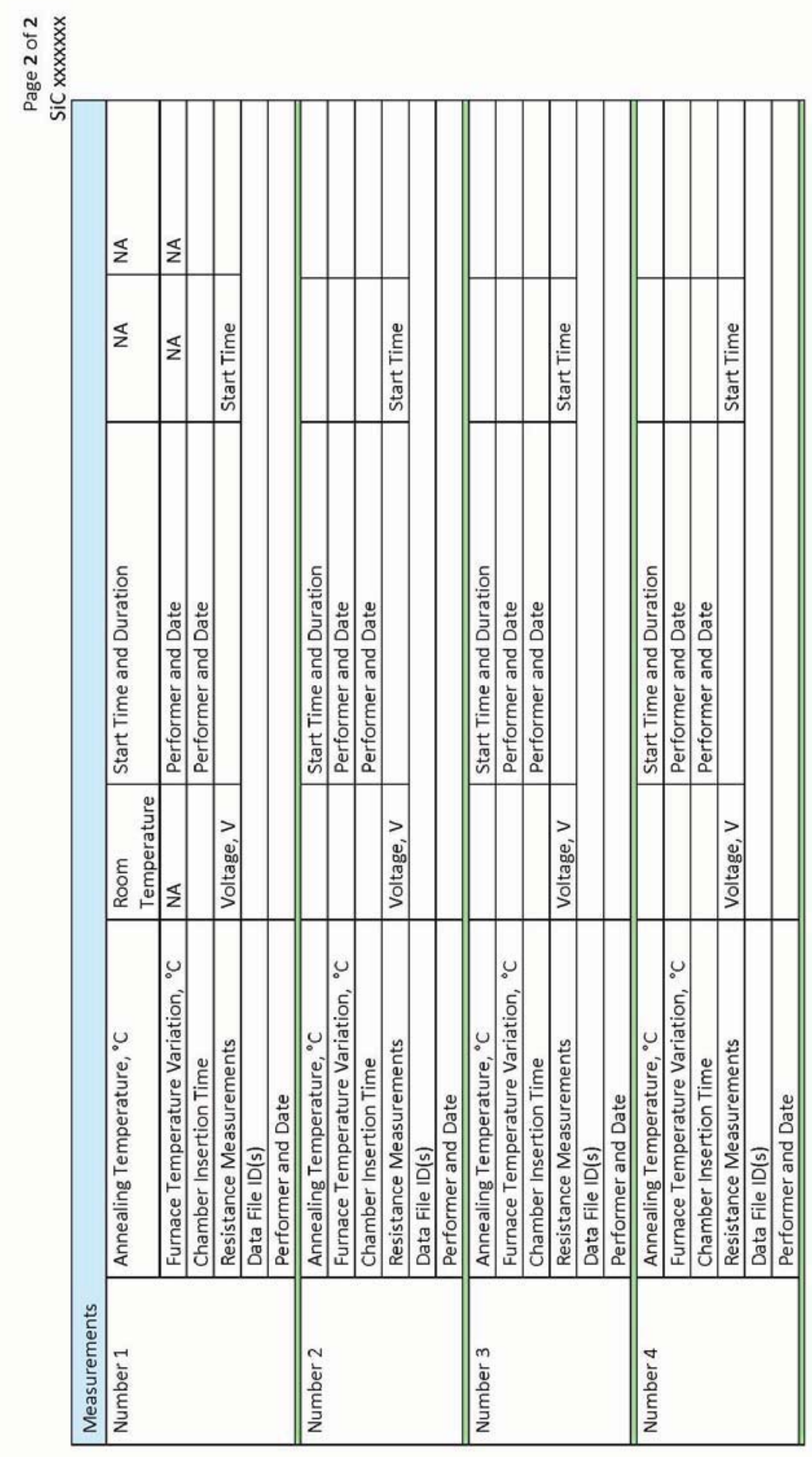


